\title{
Heródoto, V, 19-21: Alejandro I de Macedonia o el cruce de un límite heredado
}

Herodotus, V, 19-21: Alexander I of Macedon.

Beyond the Inherited Bounds

Gastón Javier BASILE

Universidad de Buenos Aires, Argentina gastonjbasile@yahoo.com

\begin{abstract}
Resumen: En V, 19-21, Heródoto narra la escena de la recepción de embajadores persas en la corte macedónica por parte de Amintas I y su hijo Alejandro I. El episodio introduce un 'corte' en varios niveles del relato herodoteo y se caracteriza por la ambivalencia en el encuadre, la caracterización y el lenguaje empleado. Dicha ambigüedad se expresa, por un lado, en la inadecuación del lenguaje de la xenía en la presentación del contacto entre pueblos, que prefigura la irrupción del 'otro' como bárbaro en las Historias. Por otro lado, la caracterización identitaria de Alejandro I —así como la identidad de los macedonios como grupo social — aparece presentada de manera ambigua entre un ethos 'griego' y uno 'no-griego.
\end{abstract}

ABSTRACT: In V, 19-21, Herodotus narrates the reception of the Persian envoys by Amyntas I of Macedon and his son, Alexander I. The episode signposts a 'turning-point' at various levels in the Herodotean narrative and displays an ambivalent framing, characterization and language. Such ambiguity manifests itself, for one thing, in the inadequacy of the language of xenía as a means of portraying the contact between social groups - which foreshadows the emergence of the 'other' as barbarian in the Histories. Furthermore, Alexander's individual identity, as well as the Macedonians' social identity, is ambiguously depicted between a Greek and non-Greek ethos.

Palabras ClaVE: Heródoto, Alejandro I, macedonios, xenía, identidad.

KeYwords: Herodotus, Alexander I, Macedonians, Xenia, Identity.

RECIBIDO: 9 de junio de 2014 - ACEPTADO: 24 de marzo de 2015.

En el libro V (19-21) de las Historias, Heródoto refiere una escena situada geográfica y simbólicamente en los 'márgenes' del espacio helénico del relato, donde se introduce formalmente a Alejandro I de Macedonia. Este episodio ha suscitado el interés de la crítica desde enfoques analíticos diferentes, aunque también, en buena medida, complementarios. La escena narra in nuce el arribo de la embajada persa enviada por Megabazo (verosímilmente en torno al 512) y su recepción por Amintas I, a la sazón rey de los macedonios. A continuación, en el contexto de un banquete entre persas y macedonios se produce un incidente que culmi- 
na con la muerte de los siete legados persas, quienes habían ofendido las costumbres locales. La muerte de los embajadores persas aviene como resultado de un ardid planeado por Alejandro I, hijo del monarca.

La escena ha generado más interrogantes que certezas, tanto en lo relativo al contenido fáctico que se pueda derivar del microrrelato, cuanto de su potencial significado alegórico — que estaría modelado sobre datos genuinos recabados por Heródoto o versiones literarias en la propia Macedonia - o de su funcionalidad en el desarrollo de la trama, en especial, como caracterización de la personalidad del ambivalente Alejandro. Ha primado, no obstante, el interés histórico (o historiográfico) en la consideración del episodio antes que un abordaje que intentara dar cuenta de su importancia estructural a nivel del desarrollo de la trama. En buena medida, se ha transformado - en conjunto con algunas otras referencias sumarias que provee Heródoto ${ }^{1}$ - en un locus textual obligado para historiadores y antropólogos dedicados a la reconstrucción de la controvertida cronología de los acontecimientos sociopolíticos de la antigua Macedonia, así como su organización sociocultural y su (indefinidamente controvertida) filiación étnica. El hecho se debe a que los datos que provee Heródoto en relación con los macedonios entre fines de la época arcaica y principios del siglo $\mathrm{V}$ son, por lo general, las únicas referencias que se poseen (o las más directas) sobre este oscuro período de un pueblo que, por añadidura, ha sido, desde la Antigüedad, ubicado en un incierto middleground entre lo griego y lo bárbaro. En efecto, la mayor parte de la información literaria sobre Macedonia deriva de fuentes (no-macedonias) tardías y se centra en especial en las campañas de Alejandro Magno; las inscripciones macedonias en época clásica son, por su parte, sumamente escasas y los historiadores clásicos que proveen datos sobre este pueblo - Heródoto y Tucídides - sólo ofrecen referen-

${ }^{1}$ Acerca de Macedonia o los macedonios en Heródoto, las referencias comienzan a partir del libro V: su acceso desde el este (V, 17); los embajadores persas enviados en época de Amintas I (V, 18-20); su sumisión a las huestes de Mardonio (VI, 44); los pasos desde Macedonia a Tesalia (VII, 128, 173); los macedonios enlistados en el ejército de Jerjes (VII, 185) y en Platea (IX, 31); relato sobre los orígenes de la dinastía teménida (VIII, 137-139); los macedonios que gobiernan Beocia para los persas (VIII, 34).

En relación con Alejandro I, los pasajes relevantes son: V, 19-21 (su participación en la recepción de los embajadores persas); V, 22 (su reivindicación de su linaje griego); VII, 173 (su advertencia a los griegos en el valle del Tempe); sus ancestros (VIII, 137139); su función de intermediario entre Persia y los atenienses y espartanos (VIII, 140144); la información brindada a los griegos antes de la batalla de Platea (IX, 44-46). 
cias circunstanciales en las que el foco de interés reside en el accionar de las póleis griegas y no en aspectos institucionales o políticos de los macedonios per se. De allí que la alusión a este pasaje herodoteo ha sido obligada en cualquier especulación sobre las características tempranas de la monarquía macedonia, la sucesión dinástica entre Amintas I y Alejandro I (posteriormente apodado 'Filoheleno') y su controvertida cronología, los nómoi arcaicos de la sociedad macedonia y su ambivalente relación geopolítica con Oriente y Grecia peninsular.

Mucha especulación historiográfica descansa pues sobre la interpretación de un pasaje cuya historicidad, ${ }^{2}$ paradójicamente, ha sido en líneas generales objetada sin reversas. Algunas de las incertidumbres historiográficas que ha planteado el relato se vinculan a ciertas inconsistencias más generales en los datos que provee Heródoto acerca de la presencia y acciones de Megabazo en Europa, quien había recibido órdenes del Gran Rey de conquistar Tracia y dominar a todos los pueblos de la región (V, 1-2), el incidente de los legados persas en Macedonia y la posterior expedición de Mardonio de 492. En VI, 44 se dice que Mardonio "incorporó Macedonia

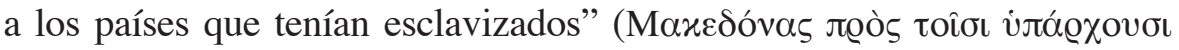

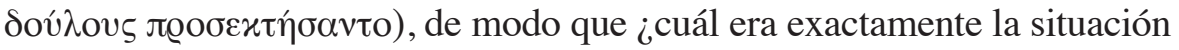
de los macedonios en aquel período intermedio, luego de la incursión de Megabazo en 512? ¿Estarían efectivamente sometidos al Gran Rey desde aquel primer contacto o cuál sería su condición? El introito que hace Heródoto a la escena del banquete, que analizaremos a continuación, parecería, en efecto, indicar la aquiescencia al dominio persa (V, 18.1):

Cuando estos persas enviados [s.e. por Megabazo] a Amintas llegaron, yendo en presencia de Amintas, reclamaron tierra y agua para el rey Darío

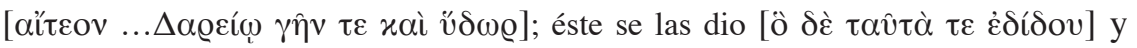

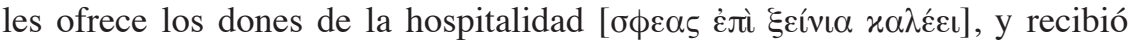

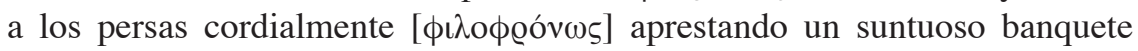

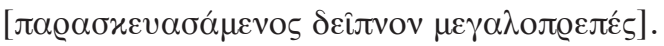

El texto efectivamente indica la entrega de los presentes solicitados por los persas, mediante la fórmula típica de la diplomacia ("tierra y agua"). Sin embargo, en la actualidad, el significado preciso de la frase ha comenzado a ser interrogado, en el sentido de que podría indicar algo

${ }^{2}$ Entre quienes rebaten la historicidad del episodio cf. Badian 1994, pp. 108-109; Fearn 2007, p. 115; Hammond-Griffith 1979, II, pp. 98-99. 
diferente a la sumisión incondicional al Gran Rey, ${ }^{3}$ que es el modo en que en general se ha entendido. Asimismo, la escena que se desarrolla a continuación no parece completamente encuadrada en términos de some-

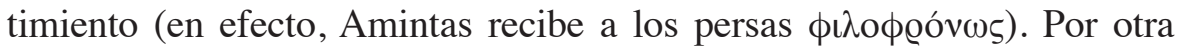
parte, tras la afrenta a los embajadores persas, Alejandro — según relata Heródoto- entregó a Búbares, hijo de Megabazo, una elevada suma de

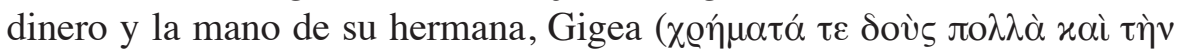

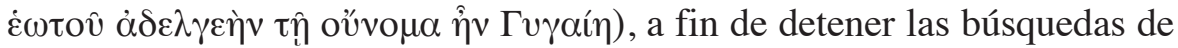
los embajadores persas desaparecidos y acallar las circunstancias (V, 21).

Este último hecho ha gozado, entre los historiadores, ${ }^{4}$ de mayor credibilidad que el relato acerca del asesinato de los siete persas y estaría señalando algún tipo de vinculación de sangre (por matrimonio) entre la nobleza persa y la monarquía local macedonia, aunque existen controversias acerca del significado político de dicha alianza. ${ }^{5}$ En efecto, la narración de estos hechos confusos presumiblemente acaecidos en torno al 512 - la aceptación de la petición de "tierra y agua" de los enviados persas (¿petición de sumisión?; ‘ ¿aceptación de relaciones amistosas con los persas sin connotaciones de vasallaje? ${ }^{7}$ ); la ulterior afrenta a los embajadores (¿disolución de la alianza?; ¿abierta hostilidad al dominio persa?; ¿signo de que la sumisión jamás tuvo lugar?) y, por último, el matrimonio de Gigea con Búbares (¿índice de rehabilitación de las relaciones amistosas?; ¿signo de la efectiva subordinación de los macedonios al imperio persa?) — no se aviene fácilmente con la afirmación

${ }^{3}$ Cf. Kuhrt 1988, pp. 87-99; Nenci 2001, pp. 31-42. En efecto, la fórmula podía implicar en la mayoría de los casos no un control directo del territorio sino más bien la hegemonía del Gran Rey sobre un gobernante local. Cf. Heródoto, IV, 126-32, donde se describe el intercambio entre Darío I y el jefe de los escitas.

${ }^{4}$ Cf., por ejemplo, Badian 1994, pp. 111-116.

${ }^{5}$ Errington (1981, pp. 139-43) entiende que Amintas nunca se sometió a Darío —porque si inicialmente ofreció "tierra y agua", jamás debieron llegar noticias de este hecho a oídos de Darío en virtud de la desaparición de los legados persas-. Por otra parte, el hecho de que sea Alejandro quien ofrece a su hermana en matrimonio a Búbares, junto a grandes sumas de dinero, estaría indicando que la sumisión debió producirse en tiempos de Alejandro (en torno al 492). Esta interpretación explicaría la afirmación posterior de Heródoto (VI, 44.1) según la cual efectivamente en el marco de la campaña de Mardonio se habría producido la anexión de los macedonios a las conquistas de Darío. Contra Badian 1994.

${ }^{6}$ La interpretación más extendida de la fórmula: Badian 1994, pp. 109-110.

${ }^{7}$ Cf. Errington 1981, pp. 139-314 y Borza 1990, p. 103. 
posterior de Heródoto según la cual sólo veinte años más tarde los persas habrían "incorporado a Macedonia" a sus dominios (VI, 44.1). Dicho de otro modo, ninguna certeza existe acerca de la cronología de los acontecimientos. Tampoco es posible fechar con precisión el traspaso dinástico entre Amintas I y Alejandro. ${ }^{8}$ Por último, interpretaciones sui generis sobre los escasos datos que provee Heródoto - y su reconstrucción- han generado controversias en relación con el status efectivo del reino macedonio en el contexto geopolítico de fines del siglo VI y principios del v. ${ }^{9}$

Ahora bien, nuestra lectura no buscará otorgar una coherencia histórica - acaso imposible — al episodio narrado por Heródoto, sino que indagará acerca de su relevancia estructural y su significado. En particular, entendemos que, en lo que respecta a la estructura de trama, el microrrelato introduce un 'corte' en varios niveles del relato. Asimismo, creemos que la presentación de los acontecimientos, los personajes involucrados y el lenguaje utilizado por la voz narradora en la ‘escenificación' del encuen-

${ }^{8}$ El relato herodoteo corre literalmente de la escena narrativa a Amintas, a partir de su relevo en el banquete por parte de su hijo, Alejandro, quien en aquel momento debía ser apenas un adolescente. Nada más se nos informa sobre su reinado, con excepción de un pasaje en V, 94 en que se nos informa que "Amintas de Macedonia le ofreció (a Hipias) Antemunte". En este sentido, comenta Badian (1994, p. 112) que la transición entre el reinado de Amintas y Alejandro sólo se puede proponer "dentro de límites amplios": sólo se sabe 1) que Amintas continuaba siendo rey hacia (probablemente) 506/5, cuando ofreció Antemunte a Hipias como retiro tras la expulsión de Atenas (V, 94.1) y 2) que Alejandro era rey a la llegada de Jerjes. En todo caso, las imprecisiones cronológicas nos enseñan que los motivos narrativos de Heródoto - la focalización sobre determinadas figuras narrativas como Alejandro- no siempre convergen con la datación precisa de los hechos. A partir del episodio de V, 19-21, Amintas es literalmente corrido de la escena de la narración y es suplantado por su hijo Alejandro, independientemente de las reconstrucciones históricas que suelen fechar su reinado entre el 495 (o 498) y 454.

9 a) Balcer (1988, pp. 1-21) propone a Macedonia como un estado semi-autónomo bajo Amintas (nunca una verdadera satrapía, sino que habría estado gobernada por oficiales enviados por el sátrapa de Sardes); b) Badian (1994, pp. 113-114) indica que la relación implicaba el reconocimiento de la soberanía persa y el pago de tributo (chrémata pollá' en Heródoto) y que Amintas sería una suerte de "sátrapa local" —un gobernante nativo nombrado sátrapa- del Rey, que mantenía cierto grado de autonomía (hýparchos, en términos de Alejandro); c) Borza (1990, p. 103) entiende que no existe evidencia de que efectivamente Amintas fuera "vasallo" del Rey; a su vez, indica que el matrimonio de Gigea con Búbares significa "alianza" y no indica que una de las partes fuera "vasalla" de la otra. Contra Badian (1994, p. 110), quien sostiene que el único tipo de alianza que el Gran Rey ("Rey de todas las tierras y todos los hombres") aceptaría era la sumisión. 
tro entre macedonios y persas se ve dominado por una evidente 'ambigüedad', ambivalencia esta que se proyecta desde el plano léxico hasta la ubicación del episodio y los rasgos de su protagonista en la macro-estructura de las Historias. En particular, intentaremos dar cuenta del modo en que dicha ambivalencia o ambigüedad se expresa en $a$ ) el esquema conceptual y el lenguaje de la xenía como mecanismo de conceptualización y codificación de los contactos entre pueblos, hecho que sugiere su agotamiento o inadecuación como modo de representar las relaciones con el 'otro' en el relato; $b$ ) la representación identitaria de Alejandro I de Macedonia ad locum y el modo en que se confirma en sus esporádicas pero significativas reapariciones en los acontecimientos de las segundas Guerras Médicas y c) la caracterización étnica general del pueblo macedonio en la obra, aspecto éste que constituye una de las preocupaciones específicas del historiador en otros pasajes (V, 22 y VIII, 137-9).

\section{La inadecuación del lenguaje y el esquema axiológico de la xenía}

El episodio de los embajadores persas en Macedonia constituye, a nuestro entender, la primera indicación inequívoca del trazado de un corte. Dicho corte - cuyas características intentaremos precisar a continuación- se produce a su vez en un espacio textual de 'transición'. En otros palabras, 'corte' en un modo dominante de representación de la identidad en el relato hasta su gradual resquebrajamiento a partir del libro V; 'frontera' —en cuanto Macedonia y su pueblo han sido en la Antigüedad griega posicionados, territorial y étnicamente, en un middleground- - y 'transición' en la narración histórica de los acontecimientos entre los antecedentes de las Guerras Médicas y los primeros enfrentamientos bélicos en el libro VI. Corte, frontera y transición se anudan en torno a este episodio que protagoniza Alejandro de Macedonia, precisamente, también a partir de un 'corte' con su padre Amintas. ${ }^{10}$

En efecto, el episodio se inscribe en el tránsito entre los libros IV y VI —en un spatium narrativo en el que tradicionalmente la crítica entre-

${ }^{10}$ Bowie (2003, p. 107) sugiere que el asesinato de los persas simboliza, a partir de la restauración de las normas del banquete 'griego', la consolidación del propio poder regio de Alejandro. Fearn (2007, p. 102), por su parte, trae a colación detalles del texto que impiden pensar en Alejandro como un restaurador de las normas civilizadas del banquete griego. 
vió un pasaje entre los lógoi iniciales, en los que se ha querido situar un interés más propiamente etnográfico-descriptivo y los lógoi finales en que despuntaría un Heródoto 'historiador' —. ${ }^{11}$ No sólo traza el límite estructural entre el libro IV y el VI, sino que marca también la transición entre la época arcaica y la época clásica (el episodio se sitúa cronológicamente en tránsito del reinado de Amintas I - quien ya gobernaba al momento en que los persas conquistaron a los peonios, ca. 512 - y el reinado de su sucesor en los inicios del siglo v). En especial, el episodio narrado por Heródoto evidenciará $a$ ) la inadecuación del lenguaje de la 'amistad ritualizada' como esquema simbólico para narrar el contacto entre determinadas figuras de elite — que se hallan en los 'márgenes' de la 'helenidad'—; b) el resquebrajamiento (o cuestionamiento) de la institución de la xenía -basada en una concepción aristocrática del otro como 'igual'- como mecanismo de codificación de las relaciones intercomunitarias; c) el paulatino surgimiento de la concepción del 'otro' como bárbaro en el relato cuya alteridad se cimentará en criterios étnicos, culturales y políticos- ${ }^{12}$

${ }^{11}$ Fearn (2007, p. 98) emplea el término "puente" (bridge) para aludir al episodio de V, 17-21, ya que efectivamente conecta el relato sobre la invasión fallida a Escitia por Darío en el libro IV y la Revolución Jonia y la subsiguiente invasión persa de Grecia en los libros V y VI; la narración del episodio sigue inmediatamente a la deportación de los peonios de Tracia a Persia por instrucciones de Darío en los primeros dieciséis capítulos. Sobre la función estructural de 'puentes' en la trama de los libros V y VI, cf. Irwin-Greenwood (2007, p. 12): "Los libros 5 y 6 sirven como libros 'puente' que contienen lógoi sobre los griegos en transición"; Irwin (2007, p. 43): "en conjunto los libros construyen un puente entre las dos mitades de las Historias, la ostensiblemente etnográfica y la predominantemente histórica, a través de una estructura al tiempo descrita como una alternancia de dos modos narrativos diferentes, y un quiasmo, en el que lógoi de brevísima extensión son flanqueados por narrativas históricas y etnográficas más extensas que las preceden y siguen"; Greenwood (2007, p. 128): "La imagen del puente es consustancial al espíritu del volumen que intenta identificar y explicar conexiones entre los diferentes lógoi en las Historias de Heródoto".

${ }^{12}$ En relación con la representación del bárbaro en las Historias, es obligado citar el seminal estudiode François Hartog, Le Miroir d'Hérodote (1980), dedicado a la cuestión de la alteridad y su representación en las Historias a partir de un enfoque enmarcado en el nuevo historicismo, a la vez que tributario del estructuralismo. La tesis fundamental de Hartog es que Heródoto clasifica la realidad de los otros, es decir, de los pueblos examinados, a la luz de categorías griegas, de modo que dicha 'retórica de la alteridad' en definitiva no es sino un espejo por medio del cual los griegos se contemplan a sí mismos, sus instituciones, valores y costumbres, es decir, se interrogan acerca de su propia identidad. El mérito del trabajo reside en su consideración del fenómeno en términos de totalidad, es decir, en explorar en el texto los modos antinómicos en que parecen organizarse simbólicamente las diferencias culturales y que determinan recíprocamente 
No se trata, empero, de un cuestionamiento teórico de la xenía sino más bien de una dramatización, dramatización cuyas coordenadas de interpretación no resultan del todo precisas —especialmente para la labor de reconstrucción historiográfica que ha procurado exhumar algún indicio de verdad acerca de las relaciones entre los macedonios y persas en este período. En efecto, en el pasaje prima la ambigüedad. ${ }^{13}$ En lo que concierne a un análisis discursivo del episodio, la ausencia de certezas históricas acerca de la naturaleza del vínculo entre macedonios y persas en este período histórico impide formular interpretaciones categóricas. Se ha especulado, no obstante, con la posibilidad de que el relato que refiere Heródoto tenga sus orígenes en propaganda macedonia tendiente a 'encubrir' o 'distorsionar' la efectiva sumisión de los macedonios al poder persa a partir de la escenificación de un conflicto entre las partes originado en el marco de un festín.

Nuestra primera lectura es que el episodio, entre otras cosas, dramatiza por primera vez en el relato las limitaciones del esquema axiológico de la xenía como modo de conceptualizar al otro. ${ }^{14}$

los modos de ser 'griegos' en contraposición a los 'otros' modos, ajenos a la 'grecidad'. Hartog explora en su estudio el maniqueísmo y la polaridad antinómica inherente al empleo de la categoría de 'bárbaro' por oposición al 'griego'.

${ }^{13}$ Por cierto, la duplicidad o ambigüedad es la marca distintiva de Alejandro de Macedonia tanto en ésta como en las ulteriores apariciones en la saga. Véase supra n. 39.

${ }^{14} \mathrm{La}$ aportación fundamental en materia de la institución de la xenía en el mundo griego corresponde a la tesis de Herman (1987) quien —abonando en las observaciones iniciales de Finley (1954) sobre la centralidad de dicho mecanismo de sociabilidad en el mundo homérico- ofrece un documentado estudio sobre los mecanismos rituales de interacción entre miembros de elite de diferentes unidades sociales en el período arcaico y clásico griego. Dichos lazos de amistad ritualizada, que podían establecerse entre miembros de distintas póleis griegas, así como entre griegos y no-griegos, o entre pueblos no-griegos entre sí, son encuadradas por Herman en la intersección de un espectro más amplio de relaciones sociales definidas por Pitt-Rivers (1973) como 'amistosas': especialmente, las del parentesco y la amistad. Se trataba de una institución esencialmente aristocrática, entre miembros de elite pertenecientes a dos unidades sociales (al menos, simbólicamente percibidas como) 'diferentes'. Asimismo, el vínculo de xenía adquiría — análogamente a las relaciones de parentesco- un carácter vitalicio y transgeneracional. Sancionada a través de una serie de rituales codificados, la institución de la xenía preveía una serie de servicios y favores, privados y políticos entre los contrayentes, gobernados por la lógica de la reciprocidad.

La institución de la xenía, de orígenes arcaicos, subsistió en los siglos v y IV amoldándose con mayor o menor efectividad a las exigencias de lealtad a la pólis y a las obligaciones respecto de los conciudadanos. Herman (1987, pp. 156-161) ha insistido 


\section{Citemos el episodio in extenso: ${ }^{15}$}

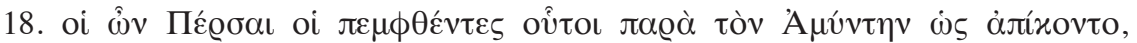

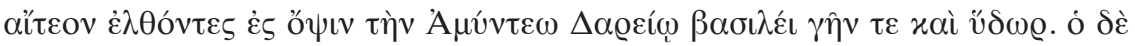

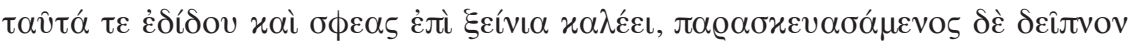

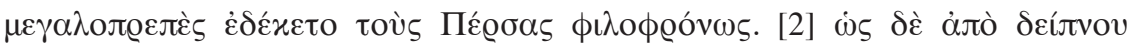

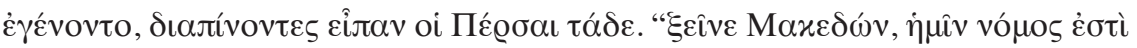

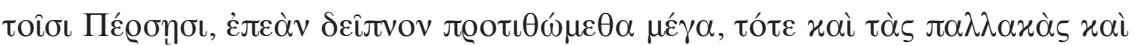

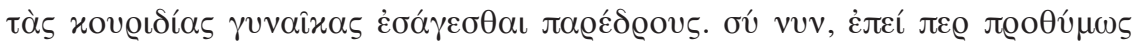

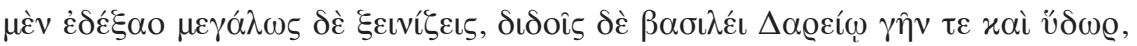

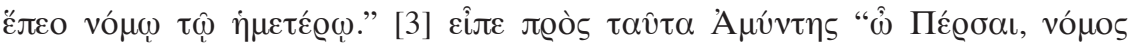

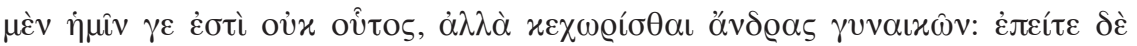

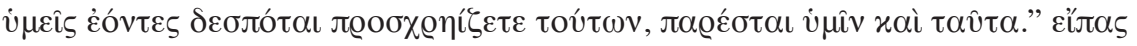

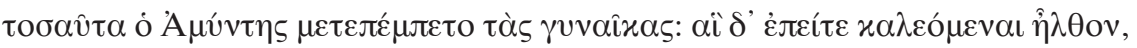

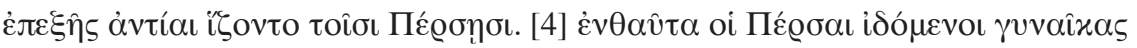

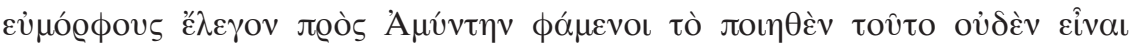

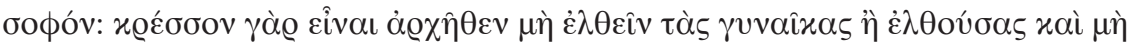

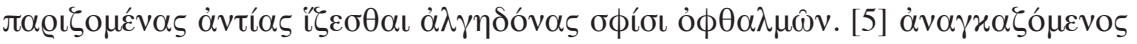

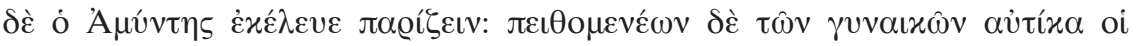

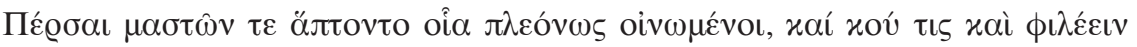

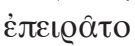

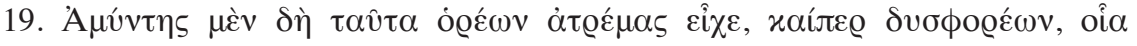

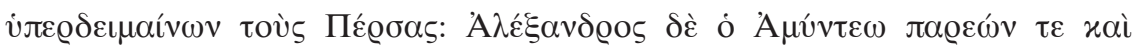

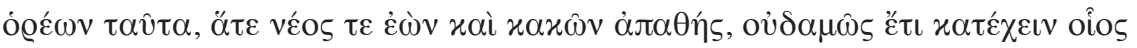

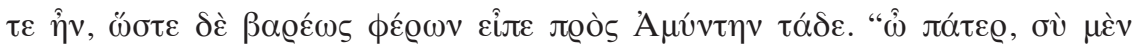

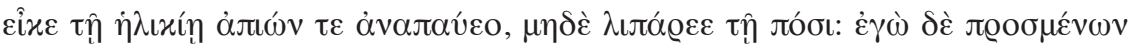

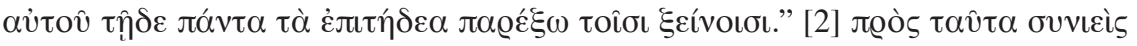

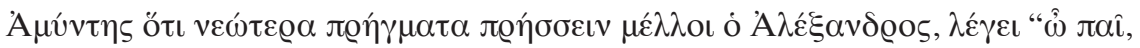

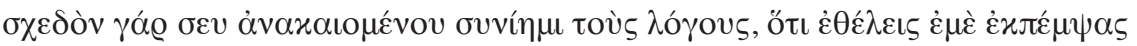

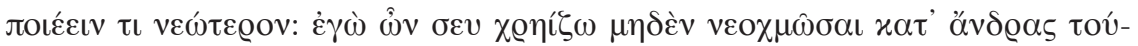

en el rígido antagonismo entre los intereses privados de los miembros de elite consolidados a través de alianzas de amistad-ritualizada, por un lado, y los intereses cívicos reivindicados por el dêmos, por otro; Mitchell (1997, pp. 50-55) propone un modelo más matizado en el que las relaciones de tipo personal-privado basadas en la philía y, en particular, aquellas sancionadas con miembros de otras comunidades a través de la xenía, podían ser convenientemente aprovechadas en la gestión de los asuntos interpóleis, si bien los conflictos de intereses y lealtades entre phíloi y los intereses de la pólis irrumpían con frecuencia y se manifestaban con la forma de acusaciones de traición a la pólis o de imputaciones de sobornos y prebendas.

15 Seguimos la edición de Godley (1946). Las traducciones son nuestras, a menos que se indique lo contrario. 


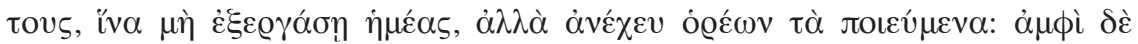

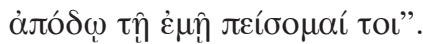

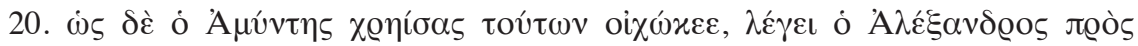

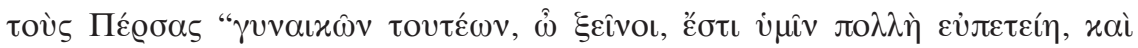

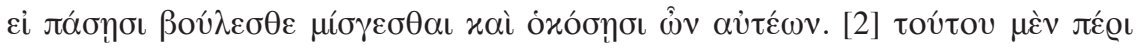

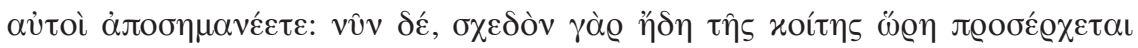

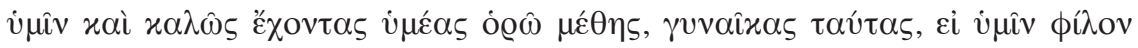

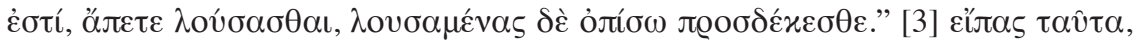

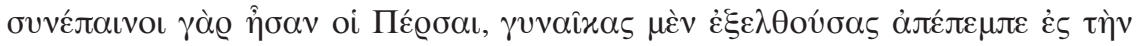

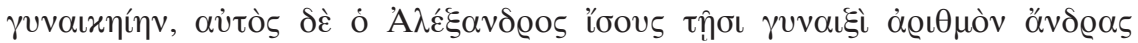

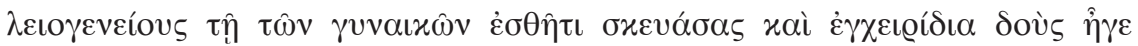

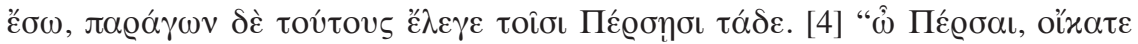

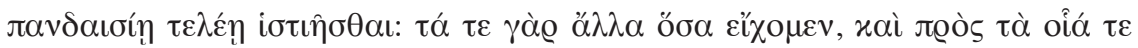

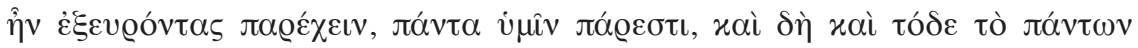

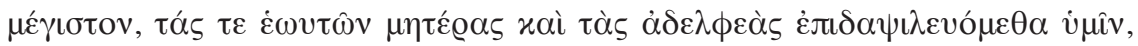

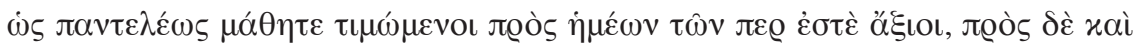

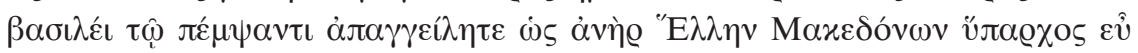

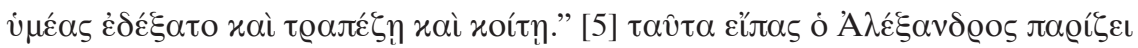

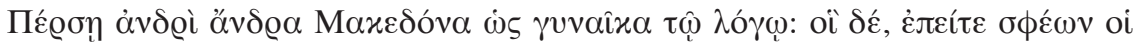

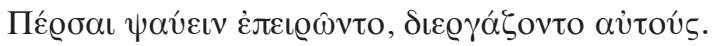

18. Cuando estos persas enviados [s.e. por Megabazo] a Amintas llegaron, yendo en presencia ${ }^{16}$ de Amintas, reclamaron tierra y agua para el rey Darío; éste se las dio y les ofreció los dones de la hospitalidad, ${ }^{17}$ y recibió a los per-

${ }^{16}$ El texto griego dice $\dot{\varepsilon} \lambda \theta o ́ v \tau \varepsilon \varsigma$ غ̇ऽ ó $\psi \iota \nu$, es decir, lit. "yendo a la vista". La importancia de lo visual - y el campo semántico de la visión- es central en el desarrollo de

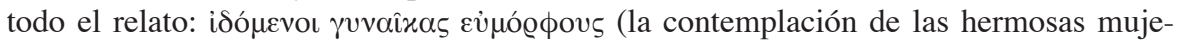

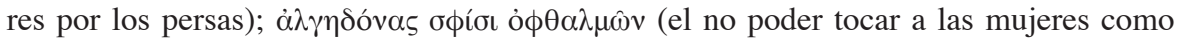

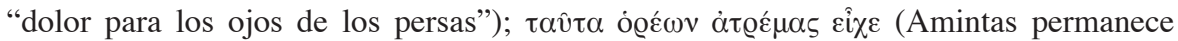

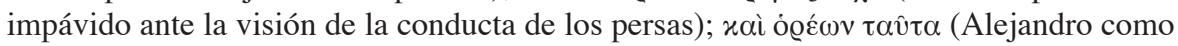

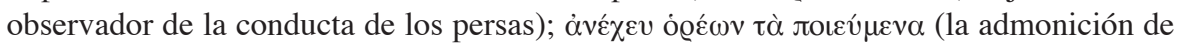
Amintas a su hijo para que permanezca como espectador sin involucrarse en la escena). En relación con el lenguaje de la visión en el micro-relato, que le conferiría un carácter dramático-visual, cf. Fearn 2007, pp. 102-103.

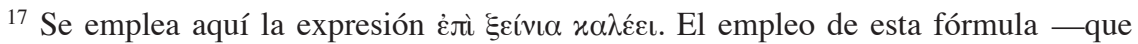
indica la recepción en el ốkos y la equiparación entre anfitriones y huéspedes en torno a la mesa convivial- inscribe, según veremos, el episodio dentro de la matriz conceptual de la xenía. No obstante, cierta inadecuación comienza ya a perfilarse desde el introito del relato, pues el agasajo de los huéspedes ocurre en correlación con la entrega de "tierra y agua" a los persas por parte de Amintas, hecho que en rigor subvertiría la horizontalidad del vínculo entre iguales yuxtaponiéndola con una relación política de tipo vertical patronus / cliens. Más aun, la asimetría de poder — que en las escenas de xenía 
sas cordialmente ${ }^{18}$ aprestando un suntuoso ${ }^{19}$ banquete. Y cuando terminaron el convite, los persas que bebían uno más que el otro, ${ }^{20}$ dijeron esto: "Huésped macedonio, entre nosotros es costumbre, después de que servimos un gran banquete, que entren y se sienten junto a nosotros las concubinas y esposas legítimas. Tú, pues, ya que entusiastamente nos acogiste, nos brindas hospitalidad con magnificencia y entregas al rey Darío tierra y agua, ${ }^{21}$ sigue nuestra costumbre". A esto dijo Amintas: "Oh persas, para nosotros en verdad la costumbre no es ésa, sino el que los hombres estén separados de las mujeres, pero pues vosotros, que sois los dueños, ${ }^{22}$ pedís además esto, lo tendréis". Habiendo

al modo homérico favorecería al xénos-anfitrión, que es quien concede el 'don inicial' y por lo tanto genera la deuda de gratitud - se ve aquí trastocada por la presunta aceptación de aquiescencia de la supremacía persa.

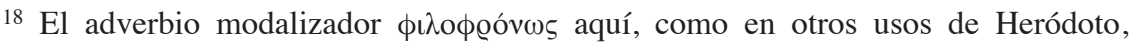
indica 'una disposición amable o amigable'. En III, 51.1 es empleado en relación con el recibimiento de los hijos de Periandro por su suegro Procles ( en III, 13.4 se utiliza para expresar la aceptación gustosa de los obsequios de los libios

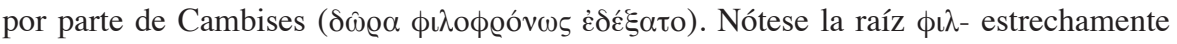
asociada a la 'amistad' ritualizada.

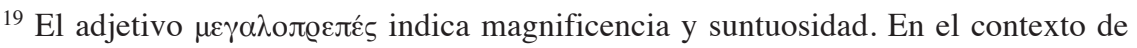
la obra el calificativo está estrechamente ligado a una conducta propia de tiranos. Cf. en relación con Polícrates (III, 125.1-2); Clístenes de Sición (VI, 128) y su magní-

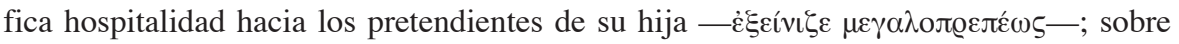
la suntuosidad y exceso en la comida propio de los comandantes persas y sus comitivas

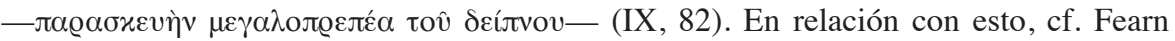
2007, p. 105.

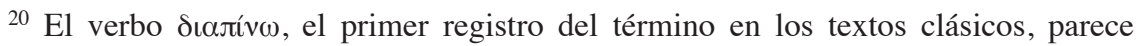
indicar aquí como en IX, 16.2 o bien que los comensales continuaban bebiendo tras la comida o bien, como hemos traducido nosotros, una competencia entre los persas por ver quién bebía más. En todo caso, el verbo connota el exceso en la bebida. (Cf.

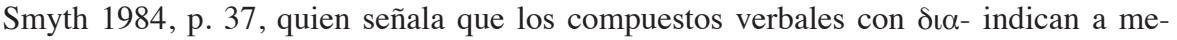
nudo intensidad, continuación o rivalidad). El motivo de la embriaguez absoluta de los persas se mantiene en el relato, por ejemplo, cuando intentan propasarse con las mujeres

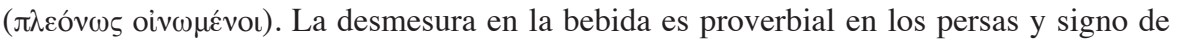
la hýbris tiránica. Sobre la función de la bebida en los sympósia en época arcaica y los banquetes macedónicos, trataremos en el cuerpo del trabajo.

${ }^{21}$ Vemos aquí de nuevo yuxtapuestos en la expresión de los persas, por un lado, el

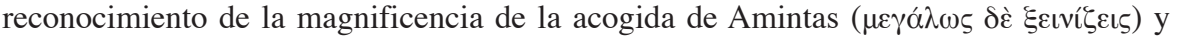

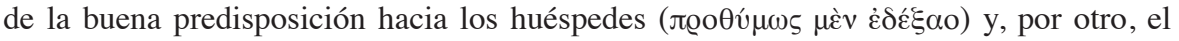
gesto de sumisión al ordo persa que evoca la entrega de "tierra y agua".

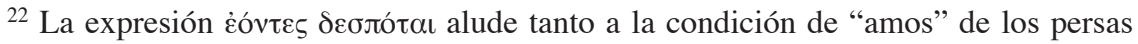
en calidad de huéspedes, cuyos requerimientos deben ser satisfechos en función de las normas de la hospitalidad, pero también en el plano político, dado que Amintas accedió al pedido de "tierra y agua". Nuevamente aquí entran en contradicción las normas de la 
dicho esas cosas Amintas, hizo venir a las mujeres. Y cuando, llamadas, llegaron éstas, se sentaron en orden enfrentadas a los persas. Al ver a esas hermosas mujeres, los persas se dirigieron a Amintas diciendo que no era nada lógico lo hecho; pues hubiera sido mejor que ni siquiera viniesen las mujeres antes que, habiendo venido y no habiéndose sentado al lado de ellos, se ubicaran enfrente como tormentos para sus ojos. Obligado ${ }^{23}$ Amintas, mandó a las mujeres a que se sentaran al lado de los persas; tras obedecer las mujeres, de inmediato los persas, como estaban completamente ebrios, empezaron a tocarles los pechos y quizá alguno intentó también besarlas.

19. Amintas, viendo esto, permanecía impasible, aunque le embargaba la indignación, porque sentía gran temor a los persas. ${ }^{24}$ Pero Alejandro, hijo de Amintas, que se hallaba presente, viendo también estas cosas, como era joven y no había sufrido males, no fue capaz de contenerse más, de modo que, apenas soportándolo, dijo a Amintas: "Tú, oh padre, ten en cuenta tu edad; retírate a descansar y no persistas en el festín; yo, permaneciendo aquí mismo, ofreceré a los huéspedes todas las cosas convenientes. ${ }^{25}$ Habiendo comprendido ante esto Amintas que Alejandro iba a cometer acciones osadas, ${ }^{26}$ le dijo:27 "Oh hijo, casi comprendo tus palabras; como estás enardecido,

hospitalidad — que prescriben el agasajo del huésped— con una situación de coerción impuesta por el sometimiento político al otro.

${ }^{23} \dot{\alpha} v \alpha \gamma x \alpha \zeta o ́ \mu \varepsilon v o \zeta$, obligado, tanto por la condición de xénoi de los persas, pero aún más por su carácter de despótai.

${ }^{24}$ El texto revela la impotencia de Amintas ante la escena que se despliega frente a

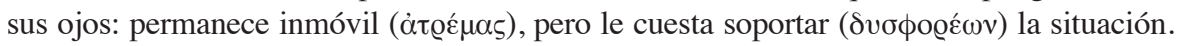

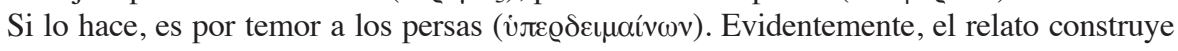
la figura de un rey complaciente ante los persas pero políticamente débil, quien será reemplazado por su joven heredero. En efecto, Alejandro hace referencia explícita a su

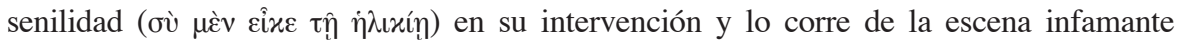
'mandándolo a dormir'. Antes de su exitus — tanto de la escena como del relato herodoteo- Amintas brinda un consejo a su hijo, función ésta que compete a los ancianos.

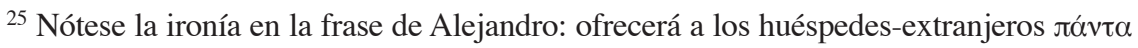

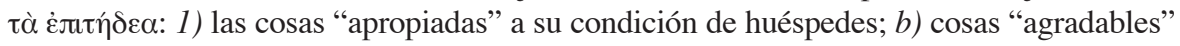
(en el sentido de las provisiones de comida, bebida y mujeres); $c$ ) las cosas que "merecen" por su ultraje a las costumbres locales.

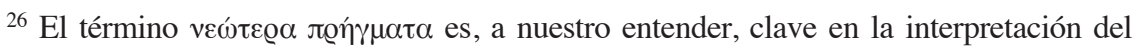
episodio y lo retomaremos en la discusión. Su uso aquí es deliberadamente ambiguo; puede significar $a$ ) 'cosas (propias de los) más jóvenes', es decir, 'juveniles'; $b$ ) 'cosas imprevistas, extrañas, de funesto auspicio'; c) 'un golpe de mano' o 'acción temeraria'; d) en Heródoto, con frecuencia también, 'un levantamiento o sublevación' (cf. V, 35; VIII, 142).

${ }^{27}$ Entendemos que el discurso de Amintas es deliberadamente oscuro en cuanto a qué es efectivamente lo que el anciano padre sospecha que Alejandro hará en su ausencia. Existe en la réplica de Amintas un vocabulario ambiguo, que permite no sólo 
quieres, alejándome, hacer alguna acción temeraria; yo te pido que no hagas nada osado en relación con estos hombres, para que no nos destruyas, sino que mantente viendo las cosas que suceden. Y en relación con mi retirada, te obedeceré".

20. Después de que Amintas, habiendo pedido estas cosas, se marchó, Alejandro dijo a los persas: "Hay completa disponibilidad de estas mujeres ${ }^{28}$ para vosotros, oh huéspedes, tanto si queréis acostaros con todas o con cuantas queráis de ellas; sobre esto, vosotros mismos indicaréis. Ahora, pues, como casi llega el momento de que os acostéis y veo que estáis bien bebidos, permitid que estas mujeres, si os es agradable, pasen al baño y, una vez bañadas, recibidlas de regreso". Habiendo dicho esto, como los persas estaban conformes, mandó al gineceo a las mujeres que habían venido. El propio Alejandro, habiendo equipado con la vestimenta de las mujeres a unos hombres imberbes iguales en número a las mujeres y entregándoles puñales los condujo dentro; y trayéndolos les dijo a los persas esto: "Oh persas, me parece que se os ha obsequiado con todo un perfecto festín: $;{ }^{29}$ pues tanto las demás cosas que tenía-

interpretar una acción necesariamente hostil hacia los huéspedes, sino que incluso puede

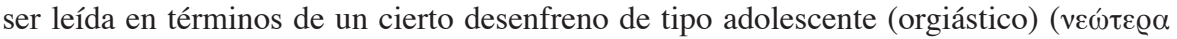

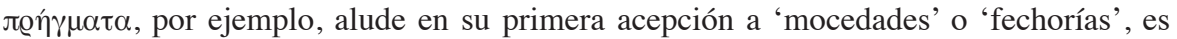
decir, a algún tipo de acción vinculada a una conducta adolescente excesiva, pero que

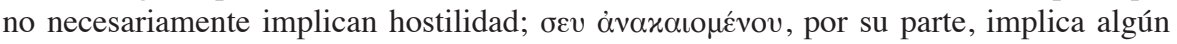
tipo de enardecimiento, inflamación o excitación de parte del joven, incluso sexual,

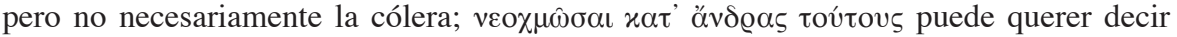
también: ‘innovar como esos hombres', en alusión quizá a un comportamiento social indebido que Alejandro imitaría de los persas —especialmente, en relación con las

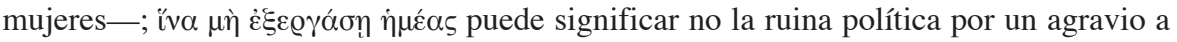
los persas, sino la ruina moral por una conducta infamante de Alejandro en su sociedad;

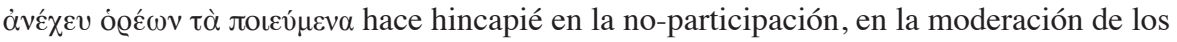
impulsos, cualesquiera estos sean). La cuestión del desenfreno (con la bebida y con el trato de las mujeres) por parte de los persas, pero también en la estratagema de Alejandro, fue puesta de relieve por Fearn (2007, pp. 112-6) quien, no obstante, no advierte las ambigüedades en la amonestación de Amintas a su hijo.

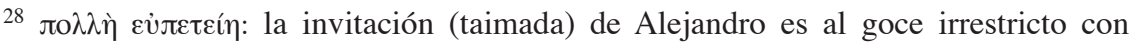
cualquiera de las mujeres. Fearn (2007, pp. 112-6) ha señalado la metáfora de la intención de violación de las mujeres por los persas como un símbolo de la dominación de Macedonia sobre el imperio persa; también ha comentado acerca de posibles alusiones a la pederastia encubiertas en el travestimiento de los jovencitos imberbes.

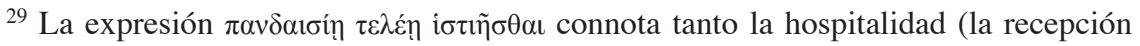

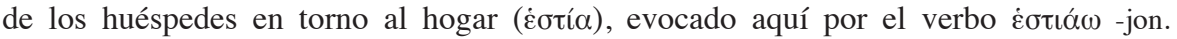

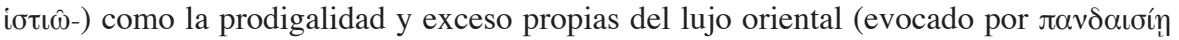

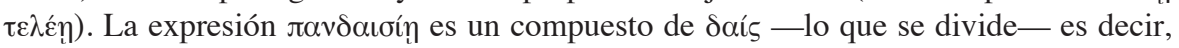

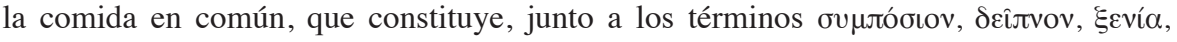
$\theta \alpha \lambda i \alpha$, etc. el vocabulario prototípico de la comensalidad en época arcaica. 
mos, como además cuantas nos fue posible hallar, todas están ante vosotros; y especialmente esto, lo más grande de todo, os entregamos generosamente nuestras propias madres y hermanas, para que comprendáis totalmente que de nuestra parte se os ha honrado como sois dignos ${ }^{30}$ y para que anunciéis al rey que os ha enviado que un griego, gobernador de los macedonios,${ }^{31}$ os recibió bien, tanto en la mesa como en el lecho". Habiendo dicho estas cosas, Alejandro ubica junto a cada persa un hombre macedonio como mujer en apariencia. $\mathrm{Y}$ éstos, en cuanto los persas intentaron tocarlos, los liquidaron. ${ }^{32}$

Sin duda, la ambigüedad es el denominador común que recorre todo el episodio, algunas de cuyas marcas hemos indicado en las notas a la traducción. De todas las posibilidades de exégesis que admite el pasaje, nos centraremos aquí en aquello que resulta más significativo a nuestros propósitos. Hemos dicho que el episodio pone de manifiesto la inadecuación del lenguaje de la xenía ante la súbita y radical irrupción del ‘otro'. Veamos en qué sentido se verifica la limitación de dicho esquema conceptual, limitación que se expresa a partir de ciertas inconsistencias o equívocos que dramatiza el encuentro entre macedonios y persas.

1) El lenguaje de la xenía parecería prima facie apropiado en las circunstancias, puesto que estaría poniendo de relieve algún tipo de alianza de clase entre 'pueblos que responden a un monarca', es decir, a dos regímenes de corte real. Si en efecto los estudios historiográficos han demostrado las sustanciales diferencias entre la autocracia personalista aqueménida y cualquier otro tipo de gobierno monárquico, el episodio no pone de relieve explícitamente diferencias de tipo constitucional; por otra parte, Heródoto no suele abundar en precisiones respecto a la organización institucional de los estados descritos en su obra. Resulta significativo, no

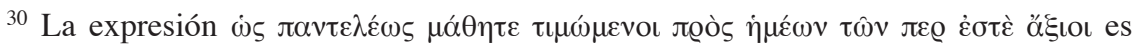
deliberadamente irónica y puede también interpretarse como "para que comprendáis totalmente que de nuestra parte se os ha condenado (a muerte) como sois merecedores".

${ }^{31}$ Comentaremos más detalladamente sobre la duplicidad de esta autodesignación hecha por Alejandro (ya en nombre propio o en el de Amintas) en la que se yuxtaponen

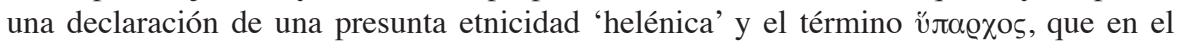
usus scribendi de Heródoto designa a los gobernadores persas (sátrapas).

32 El juego de inversiones es sugerente: si la disposición de los participantes al simposio en el imaginario griego arcaico cimentaba la horizontalidad del vínculo entre iguales, la inclusión de mujeres "sentadas al lado" ( subversión del orden esperado; la puñalada recibida, la antítesis del espíritu de camaradería y convivialidad. En este sentido, el accionar tanto de persas como de macedonios se asimila en lo que atañe a la trasgresión de los límites (la hýbris). 
obstante, que nada se nos diga en relación con Amintas al comienzo de la narración. ¿Es efectivamente el 'rey' de los macedonios? ${ }^{33}$ En todo caso, lo que importa aquí es el encuadre narrativo: Heródoto dramatiza el encuentro entre los embajadores persas y los macedonios en torno a un banquete brindado en ocasión de hospitalidad a los extranjeros, institución ésta que en el mundo griego arcaico constituía el símbolo de una práctica que cimentaba los lazos de solidaridad y reciprocidad entre iguales. No casualmente el texto es pródigo en la utilización del lenguaje de la xenía y sus cognados: el extranjero (xénos) es introducido en el círculo de phíloi que se aglutinan y reconocen recíprocamente en su igualdad de clase en torno a la '(re)partición' de los alimentos y la bebida (daís: 'división', 'ali-

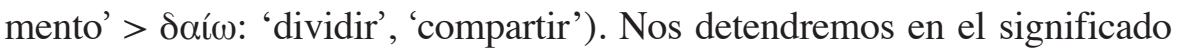
del sympósion en el apartado siguiente. Aquí veremos en qué medida la horizontalidad de clase que representa la incorporación del 'otro' al ô̂kos empieza a resquebrajarse en el pasaje. Como hemos indicado, dicha incongruencia comienza a manifestarse a nivel de la enunciación a partir del uso de determinadas expresiones que generan impresiones contradictorias:

33 Las reconstrucciones historiográficas modernas describen al estado macedonio como una monarquía hereditaria, que desciende por una única línea sucesoria desde el rey arcaico Perdicas I (originario de Argos, descendiente de Temenos, descendiente a su vez de Heracles) quien inició la dinastía, hasta Alejandro IV, hijo póstumo y cosucesor de Alejandro el Grande. En rigor, más allá de la reconstrucción dinástica que ofrece Heródoto en VIII, 137-8, nada se sabe a ciencia cierta de estos primeros reyes. Incluso de Amintas I, padre de Alejandro — cuyo reinado debió extenderse hasta el 495/8 aproximadamente en que fue sucedido por su hijo_-, la evidencia a disposición se circunscribe a este relato de Heródoto en el que, como hemos indicado, su participación es efímera y los datos son exclusivamente de carácter novelesco. Los especialistas — sobre todo a partir de testimonios más tardíos - tienden a encuadrar el régimen macedonio en un tipo de gobierno autocrático. Heródoto - quien no emplea un término ad hoc en el pasaje que nos ocupa- emplea el término basileús para referir a los gobernantes macedonios en su reconstrucción dinástica posterior (VIII, 137-8), si bien indica que Alejandro I fue el séptimo descendiente en hacerse cargo de la tiranía ( (Cf. también Tuc., II, 99, quien en su digresión sobre el estado macedonio bajo Perdicas II, hijo de Alejandro I, utiliza el término 'rey'). En general, los historiadores piensan que se trató de un régimen autocrático de carácter más bien personalista, aunque existen debates en cuanto al tipo de limitaciones que podía girar sobre la figura del rey. En lo que a nosotros compete, se trataría de una sociedad fuertemente dominada por una aristocracia de elite, caracterizada por el predominio del basileús y su círculo de hetaîroi, quienes participaban de los banquetes reales a la usanza homérica y de expediciones de caza junto al monarca. Al respecto, cf. Hammond-Griffith 1979, II, pp. 383-5; Errington 1978, pp. 77-133; Borza 1990, pp. 238-239. 


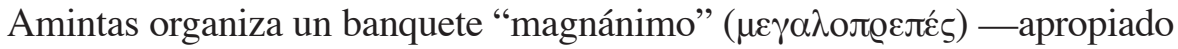
a la dignidad de clase de los enviados del rey Darío- y les ofrece hospitalidad 'de buen grado' (

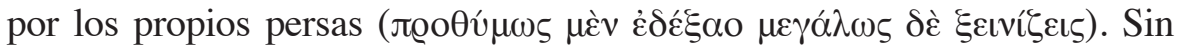
embargo, otros indicios del texto - como la entrega de "tierra y agua",

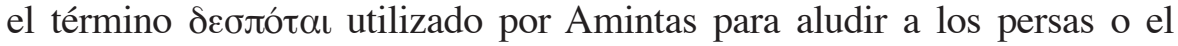
"gran temor" del macedonio hacia ellos- sugieren, en cambio, un tipo de vínculo que no descansa sobre una relación horizontal de clase en virtud de la cual el 'extranjero-que-llega' es incorporado en una sociedad de 'iguales' consolidada en torno al convivium. En efecto, la simetría que impone el lenguaje de la xenía se ve horadada por una relación vertical y asimétrica de poder que se instala desde afuera. Si efectivamente Amintas entregó 'tierra y agua' a los persas y si dicha fórmula implica sumisión completa o, al menos, como creen algunos, cierto tipo de vínculo de vasallaje, estaríamos aquí ante una lógica disruptiva de la amistad ritualizada: una relación vertical del tipo patronus / cliens.

En el plano de los hechos materiales que pudieron dar lugar al relato, algunos historiadores ${ }^{34}$ entienden que no existe evidencia de que efectivamente Amintas fuera 'vasallo' del rey. Los argumentos en este sentido se fundan en la falta de consenso en torno al verdadero sentido de la petición de 'tierra y agua', fórmula que podría implicar no una completa sumisión, y también en el dato posterior del matrimonio de Gigea, hermana de Alejandro, con el persa Bufares, hecho éste que apuntaría más a una alianza por parentesco con la elite persa que a una situación de sumisión. En rigor, en el caso en que efectivamente Amintas hubiera aceptado algún tipo de subordinación a la hegemonía persa - lo cual también

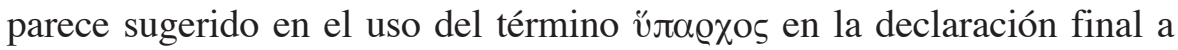
los legados-, es posible interrogarnos acerca de por qué se emplea aquí el lenguaje de la xenía para codificar un vínculo que en rigor implicaba una asimetría de poderes. Si el texto herodoteo es ambiguo - y por cierto es consistentemente ambiguo en lo que atañe a los macedonios en el relato- es, a nuestro entender, porque la xenía, presenta el contacto entre pueblos como una relación entre 'iguales' de clase cuando stricto sensu existía una situación de dominación o —en el mejor de los casos- de vasallaje sobreimpresa. En este sentido, resulta convincente la hipótesis según la cual el relato que presenta Heródoto derivaría de —o habría sido

34 Borza 1990, p. 103. 
modelado sobre - 'propaganda' promacedonia y antipersa en circulación en tiempos de Heródoto. ${ }^{35}$

2) El lenguaje de la xenía se ve aquí reforzado por el vocabulario asociado al simposio - práctica ritual que constituía el núcleo de vida social de los hombres de la aristocracia griega en época arcaica-. El significado e importancia del ritual del simposio han sido ampliamente estudiados y los autores no dudan en considerarlo una práctica social central en los mecanismos de socialización entre miembros de elite en época pre-clásica. ${ }^{36} \mathrm{El}$ simposio — tal como permiten ver las representaciones pictóricas - equipara el status de los asistentes, los homologa como una única función de clase, al punto que cada uno de los participantes parece apenas una réplica del otro: "se asemejan por sus vestimentas, sus gestos, sus posturas, sus rostros; parecen intercambiables". ${ }^{37}$ El xénos podía ser introducido a la convivialidad entre iguales que se cimentaba en torno a la repartición ritualizada de la comida y bebida en los círculos aristocráticos, inscribiéndolo, pues, simbólicamente en los mecanismos recíprocos de la philía del espacio interior de la pólis. El xénos veía, pues, su status de 'igual' confirmado

${ }^{35}$ Cf. Fearn 2007, p. 99.

36 Sobre la cultura del simposio griego, cf. entre muchos otros, Murray 1983, pp. 195-9; Murray 1990, pp. 3-13; Schmitt-Pantel 1997. Murray (1983, p. 196) caracteriza al simposio como una práctica social — la bebida en común — y una institución social, una forma privada de asociación entre individuos de elite a través de la cual "un grupo de hombres afirma su identidad". Se trata de una institución central en el mundo griego desde época homérica hasta el período helenístico, en el curso del cual ha sufrido algunas transformaciones. Los rasgos prototípicos de la institución son, según SchmittPantel (1997, p. 46-7) su carácter "masculino, aristocrático, igualitario, centrado sobre la bebida. Es el signo de un estilo de vida aristocrático. Sus funciones son múltiples dado que el simposio impregna la vida de la ciudad arcaica en todos los niveles". A grandes rasgos, la autora propone tres momentos en el desarrollo de la práctica del sympósion: 1) el simposio como herencia de la comida entre guerreros de época homérica, organizada en torno al jefe, en el seno de la cual se afirmaba y consolidaba la función guerrera; 2) a partir del siglo VII hace su aparición el sympósion propiamente dicho, de características diferentes al banquete homérico, que representa un estilo de vida aristocrático, cerrado sobre sí mismo, una evasión en el divertimento y el lujo; 3) entre la época arcaica y la clásica el simposio evoluciona en dos direcciones: por un lado, se abre a otros grupos sociales además de la aristocracia (como el grupo de lo hoplitas), donde continúa siendo un espacio de diversión y entretenimiento; por otro, el ritual del simposio se introduce en la esfera pública (como en el caso de las syssitía de las hómoioi espartiatas, o la sítēsis en el pritaneo de Atenas).

${ }^{37}$ Schmitt-Pantel 1997, p. 22. 
merced a la inscripción en el simposio entre iguales. Píndaro ${ }^{38}$ ofrece

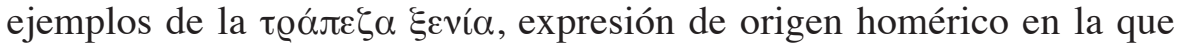
se funden la comensalidad en el interior del círculo de iguales y el deber de hospitalidad hacia el extranjero. Ahora bien, en el episodio que narra Heródoto, dicho lenguaje se ve en cierta medida subvertido. La clave aquí, según nuestra lectura, reside en la irrupción de un significante: el nómos. Ya hemos apuntado que desde el comienzo del microrrelato la inadecuación del lenguaje de la xenía podía vislumbrarse en virtud de una 'incómoda' asimetría de poderes entre los persas y los macedonios, evocada por la entrega de 'tierra y agua'. Pero el conflicto en la representación del 'otro' estalla puntualmente en un momento del episodio en que se produce un cruce de perspectivas. Los persas

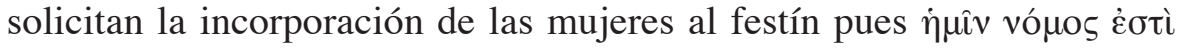

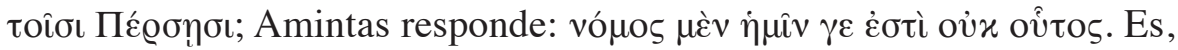
pues, el conflicto entre los nómoi macedonios —en este punto, análogos a las disposiciones griegas, que conciben la celebración de los banquetes como una práctica restringida al mundo masculino- y los nómoi persas —quienes incluyen a las mujeres en sus banquetes. ${ }^{39}$

En este sentido, el pasaje ilustra que —más allá de una presunta asimetría de poder entre las partes, sobre la cual el texto es deliberadamente ambiguo- son los nómoi persas y macedonios los que entran en contradicción y desbaratan la horizontalidad de clase que plantea el sympósion y que exige la xenía. El significante que instituye la diferencia es, pues, nómos. El 'otro' comenzará a irrumpir en el relato como un potencial trasgresor de las costumbres del in-group, subordinando su condición de igual de clase. Esta es, a nuestro criterio, la primera vez en el relato en que irrumpe esta differentia en los mecanismos de socialización interaristocráticos y que posibilitará una nueva modalidad de con-

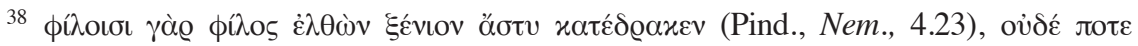

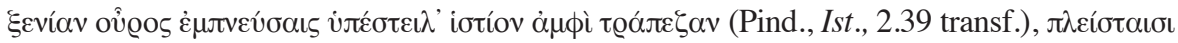

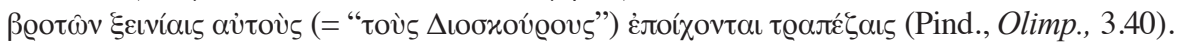

${ }^{39}$ Sobre esta costumbre persa, comenta Wiesehofer 1996, p. 85: "Todas las mujeres de la casa real, según como se las menciona en los textos de Persépolis, se muestran positivamente activas, emprendedoras y resueltas. Participan de las festividades reales y banquetes y organizan sus propias celebraciones, viajan por el país y dan instrucciones, vigilan sobre sus dominios y fuerza de trabajo, no resulta sorprendente que algunos griegos, quienes creían en el ideal de la mujer (casada) que vivía recluida y llevaba una vida irreprochable, también ubicaban a las mujeres de la familia real persa dentro de sus "casas"”. 
cebir al otro. ${ }^{40}$ De allí que hemos querido ver un verdadero 'corte' en la representación de la identidad a partir de la inserción de este episodio en la trama. En el episodio entre persas y macedonios que se inscribe en el libro V, son los nómoi persas los que por primera vez introducirán la diferencia; es precisamente dicha discordia la que comenzará a horadar a partir de aquí una concepción del otro fundada en un mecanismo aristocrático de relación entre iguales.

\section{La proclama identitaria de Alejandro I de Macedonia}

El apóstrofe final de Alejandro a los embajadores persas contiene una
sugerente autoproclamación identitaria que merece la pena examinar a

${ }^{40}$ La diferencia que instituye este micro-relato se vuelve ostensible si se lo compara con el esquema de relaciones inter-aristocráticas que Heródoto describe en los libros I a IV en los que la xenía encuadra las relaciones entre pares sin aparentes discordancias. La xenía parecería 'funcionar bien' en los primeros libros, donde se narran la historia arcaica de las relaciones intercomunitarias, pero no será así a partir de este episodio del libro V. Esto no quiere decir que las relaciones inter pares narradas en los primeros lógoi se sucedieran sin dificultades o no existieran conflictos. La diferencia es que el esquema conceptual de la xenía parecía ajustarse sin inconvenientes a los acontecimientos de la primera parte del relato en cuanto que impone una concepción del otro como igual de clase. Tomemos un ejemplo. En I, 69 Heródoto narra el episodio de Adrasto, el frigio, quien es acogido por Creso como xénos en su corte de Sardes. Tras haberlo purificado como consecuencia del homicidio de su hermano, Adrasto mata involuntariamente al hijo de Creso, traspasándolo con una punta de flecha en una cacería. Sin duda, existe un conflicto: el huésped, tras haber recibido la hospitalidad de Creso, se convierte en el homicida involuntario del propio hijo del anfitrión. Si Adrasto infringe los deberes de un 'buen huésped', esto no desacredita empero la institución de la amistad-ritualizada per se ni el esquema conceptual que impone la concepción del otro como 'igual' de clase. Tanto Creso como Adrasto - aun no siendo griegos - se conducen en función de los códigos de conducta de la xenía que gobierna el justo mecanismo de relación entre aristócratas. Aquí no irrumpe ningún nómos idiosincrásico que 'siembre' la discordia entre las partes; nada en la interacción distinguiría a un lidio de un frigio. Se trata, en todo caso, sólo de un buen / mal anfitrión o de un buen / mal huésped. Las mismas observaciones pueden hacerse respecto de los otros encuentros entre aristócratas griegos o no griegos narrados por Heródoto en los primeros lógoi. Los variados nómoi de cada pueblo que Heródoto describe puntillosamente en las secciones etnográficas descriptivas parecerían no incidir efectivamente en el tipo de relación entre las partes dramatizadas en la trama narrativa. En definitiva, hasta este episodio del libro $\mathrm{V}$ entre macedonios y persas el esquema de intercambio entre insiders y outsiders se ciñe en la obra al paradigma de la xenía more homerico. 
la luz de las ambigüedades mismas del pasaje, algunas de las cuales hemos indicado en las notas a nuestra traducción. Dice Alejandro, como fatídica anticipación del crimen que habrán de perpetrar los jóvenes macedonios travestidos: "[...] para que anunciéis al rey que os ha enviado, que un griego, gobernador de los macedonios, (ảvì "E

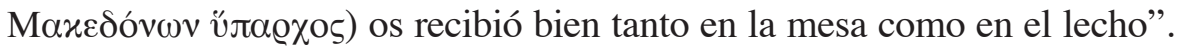
El enunciado es, en efecto, sugerente en varios sentidos: 1) por un lado, condensa toda una serie de ambivalencias que se verifican en el microrrelato vinculadas a un presunto éthos 'griego' y su imbricación con un éthos 'no-griego'; 2) en segundo lugar, la declaración en primera persona de Alejandro resulta equívoca en lo que respecta a su atribución; hecho éste que constituye un sesgo particular de otras intervenciones en oratio recta del príncipe macedonio en instancias posteriores del relato al tiempo que señalará la duplicidad como marca de fuego de su accionar posterior en la trama; ${ }^{41} 3$ ) por último, la frase constituye un locus privilegiado para indagar acerca de la controvertida adscripción étnica de los macedonios, no sólo en la historié herodotea, sino en las ambiguas percepciones que las fuentes griegas trasmiten acerca de dicho pueblo. Más aun, creemos que la proclama identitaria de Alejandro ilustra en varios sentidos la naturaleza discursiva de cualquier intento de autoatribución étnica.

1) La proclama de Alejandro, por cierto, es tan terminante y categórica como ambigua en su enunciación. Coexisten en el sintagma el gentilicio $\varepsilon \check{\varepsilon} \lambda \lambda \eta v$, por un lado, que instituye públicamente la filiación étnica de la monarquía macedonia (y, por extensión, debemos entender, el conjunto

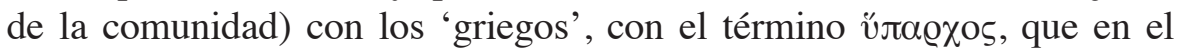
usus scribendi de Heródoto designa a los gobernadores persas (sátrapas), miembros de elite persas a quienes el Gran Rey delegaba la autoridad civil

\footnotetext{
${ }^{41}$ La segunda aparición de Alejandro tiene lugar en el libro VIII, ocasión en la que Mardonio lo convoca en calidad de embajador. Es decir que un lapso aproximado de veinte años ha trascurrido desde la escena relatada en el libro V hasta el año 479 en que acaece esta segunda intervención, en vísperas de la ocupación del Ática por las fuerzas de Mardonio y de la batalla decisiva de Platea. Mardonio le encomienda al Rey macedonio la misión de persuadir a los atenienses de que depongan las armas y se sometan voluntariamente al Gran Rey, ofreciéndoles por su intermedio seductoras ventajas a cambio de su 'medismo'. Nuevamente aquí la postura de Alejandro se ve signada por la ambivalencia, al igual que el modo en que se presenta su participación en los hechos desde el plano de la enunciación.
} 
y militar de cada una de las vastas regiones del imperio..$^{42}$ La declaración simbólica de Alejandro que anticipa el 'corte' que instituirá en el curso de los acontecimientos (corte éste que se materializará cruelmente en el cuerpo de los legados persas a manos de los mancebos travestidos) es, por cierto, ambigua. La frase prefigura, a su vez, la ambivalente actitud herodotea en lo que respecta tanto al futuro monarca macedonio - quien mediante este gesto desplaza definitivamente a su anciano padre del escenario de la enquête operando así un anticipado traspaso dinástico que no corresponde con la reconstrucción de la cronología de los reinados- así como al emplazamiento de los macedonios en el espacio simbólico del relato. En la proclamación del joven Alejandro coexisten, pues, un índice de pertenencia étnica con los griegos — dato éste que el propio Heródoto precisará a continuación en $\mathrm{V}, 22-\mathrm{y}$ un equívoco término político "gobernante (¿sátrapa?) de los macedonios" que parecería inscribir el reino macedónico dentro de la estructura administrativa del imperio aqueménida. ${ }^{43}$ Independientemente del efectivo status geopolítico de Macedonia o del cargo detentado por sus monarcas, la proclama de Alejandro pone de relieve la articulación contradictoria de un éthos griego — que deriva de un gesto de autoatribución - y la supuesta dependencia (con un variable grado de autonomía que es imposible precisar) respecto del imperio aqueménida, que estaría señalando un acercamiento o connivencia con el persa. La ambivalencia del enunciado puesto en boca de Alejandro se corresponde con los mismos sucesos de los que oficia de epílogo, cuya interpretación difumina los límites entre un éthos griego y no-griego. Si,

\footnotetext{
${ }^{42}$ Acerca de la función y atribuciones de los sátrapas ("Protectores del reino"), quienes acaparaban en torno a sí y sus descendientes directos un gran poderío personal y en ocasiones disputaban la autoridad del Gran Rey, cf. Briant 1996, pp. 350-9.

${ }^{43}$ Como hemos indicado, el efectivo status de Macedonia hacia finales del siglo VI es difícil de precisar. Aún se discute si efectivamente existió una satrapía persa denominada Skudra, que habría incluido Tracia y si los macedonios formaban parte de ella (cf. Hammond-Griffith 1979, II, pp. 59-60; Briant 1996, pp. 931-2). Asimismo, se discute cuál sería la situación de los monarcas macedonios en relación con el poder imperial persa. Badian (1994, pp. 114-115) entiende que "a cambio de su oportuno ofrecimiento de vasallaje y como recompensa por la ampliación considerable de los dominios del Rey en un área de prometedora riqueza futura, Amintas habría permanecido como lo que podríamos denominar un sátrapa local", es decir, que se trataría del primer gobernante local designado como sátrapa del que se tenga conocimiento. Otros (cf. Tri-

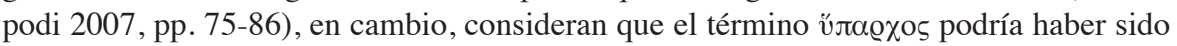
usado para designar autoridades locales de un rango inferior, dependientes a su vez de un gobernador persa asignado directamente por el Gran Rey a la región.
} 
como hemos visto, Alejandro imprime un 'corte' con el otro —evitando que los persas infrinjan los nómoi locales mediante el abuso de las mujeres y la transgresión de las normas del sympósion-, su accionar no lo posiciona empero como 'griego'. En efecto, el corte que opera Alejandro se efectiva mediante una abierta violación de la xenía, cuya expresión más radical es el asesinato de los huéspedes. Asimismo, toda una serie de indicios en el microrrelato, que se verán ulteriormente refrendados por la participación propersa de Alejandro en la narración, sugiere un modo de conducta más directamente asimilable a un estereotipo del 'bárbaro' que a un éthos griego. Una de las observaciones que se han formulado en este sentido apunta a la dinámica misma del simposio que escenifica Heródoto - $-\mathrm{y}$ que se ha visto refrendada por evidencias históricas posterioresque no permitiría encuadrar el sympósion macedónico plenamente en las pautas de convivialidad prototípicas de las póleis griegas. En efecto, existe, según hemos puesto en evidencia en nuestra traducción, todo un vocabulario vinculado al 'desenfreno' o a la voluptuosidad, así como connotaciones que apuntan al exceso en los placeres (en la comida, bebida, sexuales) que contravienen la imagen de la moderación griega y que, sin duda, aparecen sugeridas en la narración. El entendimiento entre macedonios y persas — sugerido mediante el vocabulario de la xenía - no reside únicamente en la recepción hospitalaria de miembros de elite que encarnan el poder regio (los aristócratas enviados por el Gran Rey y la monarquía macedonia), sino que parece existir cierto grado de desmesura afín a persas y macedonios. ${ }^{44}$ Cierto es que existe un límite (dramatizado

${ }^{44}$ Los sympósia de las cortes macedónicas, junto a las cacerías reales y a la institución de los paîdes —en la que los hijos de los nobles convivían y servían al rey-, constituían las tres instituciones fundamentales de la monarquía macedónica que cimentaban los lazos aristocráticos entre los miembros de elite (cf. Hammond-Griffith 1979, II, pp. 395-400; Borza 1983, pp. 45-55). Si bien los testimonios más amplios sobre la sociedad macedónica corresponden a los reinos de Filipo II y Alejandro III, la centralidad del simposio en la corte macedónica — como espacio de recreación y de contactos inter-aristocráticos y, probablemente también, de decisiones políticas- está bien documentada. El episodio de Heródoto, independientemente de su elaboración novelesca, constituye el único testimonio del desarrollo de un simposio macedónico en época preclásica. La crítica ha destacado tanto las semejanzas como ciertas diferencias — que podrían haber sido exacerbadas por un sesgo helenocéntrico de las propias fuentes - entre los usos y costumbres del simposio griego y del macedónico. Entre las semejanzas, se ha señalado el hecho de que se tratara de una actividad convivial entre miembros de elite de sexo masculino; el hábito de reclinarse en lugar de sentarse sobre los asientos, así como cierto nivel de igualitarismo entre los participantes. Entre las di- 
en el pasaje al acto de Alejandro) más allá del cual la semejanza entre los nómoi macedonios y las costumbres persas no puede proyectarse. Sin embargo, tampoco la ambientación que ofrece Heródoto puede inscribirse directamente en un éthos 'griego'. ${ }^{45}$ Alejandro se autoproclama 'griego' pero su conducta en el marco del banquete de hospitalidad a los persas no responde a un ideal del éthos helénico, aun cuando su actitud pueda verse justificada como un intento de reestablecer el imperio de nómoi 'griegos' en lo que atañe a la estricta separación de los sexos en el sympósion. En última instancia, el episodio abre interrogantes en lo que respecta a qué se entiende por ser 'griego' — término que hemos deliberadamente entrecomillado en nuestro análisis-; cuáles son los criterios de definición de una potencial adscripción identitaria, así como las fronteras simbólicas en que dicha construcción identitaria ora cristaliza ora deviene problemática.

Ahora bien, las ambivalencias que sugiere la declaración final de Alejandro, sumadas a la desmesura del castigo infringido a los persas en abierta violación de los códigos de la hospitalidad more graeco y a una deliberadamente ambigua caracterización de los nómoi macedonios en relación con las normas del simposio, se proyectan en los parágrafos siguientes. Tras el engaño y crimen de los embajadores, Alejandro — continúa Heródoto $(\mathrm{V}, 21)$ — detiene la búsqueda de los desparecidos iniciada por los persas; ofrece grandes suma de dinero y entrega a su propia hermana en matrimonio al jefe de los que encaraban

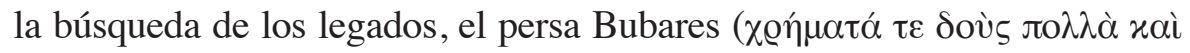

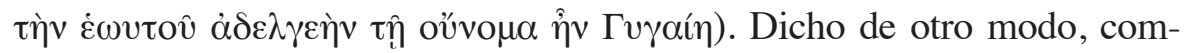
pra el silencio ( $\dot{\varepsilon} \sigma \gamma \eta \dot{\theta} \theta \eta)$ del jefe de la expedición mediante el soborno y el establecimiento de una alianza de parentesco, presumiblemente con el

ferencias, se ha destacado en cambio, una propensión al lujo extravagante y una fuerte impronta agonal entre los participantes, más afines a un cariz oriental. Asimismo, las fuentes describen los simposios macedonios como espacios en los que ocurrían excesos de toda índole: grescas entre los participantes motivadas por la bebida desmesurada, hechos de violencia y conspiraciones que podían incluso derivar en homicidios. En relación con las particularidades de los simposios macedónicos, veánse especialmente Murray 1996, pp. 15-27; Carney 2007, pp. 129-80.

${ }^{45}$ Fearn (2007, pp. 124-5) contrapone, por un lado, la filiación helénica que Heródoto trasmite en dos ocasiones y, por otro, sus acciones o conductas no-griegas - como en el episodio del simposio- o incluso abiertamente medizantes en el contexto general de las Historias. J. Hall (2001, p. 170), por su parte, sostiene que "la pretendida descendencia helénica de Alejandro no es una garantía de que actuará como griego". 
fin de no deteriorar irremediablemente las relaciones con Persia. Por lo general, la crítica ha adjudicado mayor rigor histórico a esta unión de la hermana de Alejandro con el persa Bubares - probablemente el hijo de Megabazo (VII, 22.1) — que al relato de la recepción de los legados persas dramatizada por Heródoto previamente. ${ }^{46}$ En efecto, de esta unión habría resultado el nacimiento de un hijo, bautizado Amintas en honor a su abuelo, quien habría recibido la ciudad de Alabanda en Caria como obsequio del Gran Rey (VIII, 136.1). Independientemente del significado preciso de esta unión - cuya efectiva datación ha sido puesta en duda por aquellos que desestiman la historicidad del episodio de los legados-, a nivel narrativo la referencia a esta alianza por parentesco - ya sea que se trate de un intento de recomponer las relaciones con los persas como sugiere la secuenciación de Heródoto o que marque los inicios efectivos del contacto amistoso o el sometimiento (¿voluntario?) al imperio persa - afianza la duplicidad y ambivalencia que caracterizan el accionar de Alejandro (su бoфí indefinido status del pueblo macedonio entre lo 'griego' y lo 'persa'. El contrapunto a esta referencia a la connivencia de los macedonios con los persas lo ofrece el parágrafo siguiente $(\mathrm{V}, 22)$, donde la balanza parece inclinarse en cambio a favor de la 'helenidad' de Alejandro. Dice Heródoto:

Ciertamente, la muerte de estos persas, así acaecida, fue silenciada. Pero que estos descendientes de Pérdicas son griegos, tal como ellos dicen, yo mismo sé por caso que es así y en mis relatos sucesivos demostraré que son griegos. ${ }^{47}$

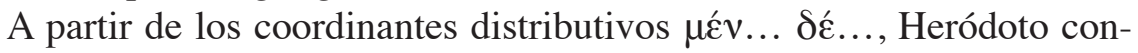
trapone, en el plano del enunciado, el relato del soborno y componenda de Alejandro $(\mathrm{V}, 21)$ — que ubicaría al rey macedonio en una posición

${ }^{46}$ Justino, historiador romano del siglo II, ofrece una versión novelada de esta alianza entre Bubares y Gigea: el persa se habría enamorado de la hija de Amintas en su incursión contra los macedonios, hecho que lo habría inducido a deponer las hostilidades a cambio de la mano de la joven. Bubares habría permanecido en Macedonia por un tiempo hasta la muerte de Amintas. Se supone que la versión que trasmite Justino habría sido elaborada tardíamente sobre la base del relato de Heródoto, de modo que poco contribuye al esclarecimiento de los hechos (Justino, L. VII, cap. 3).

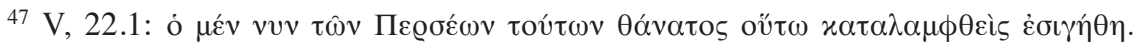
"E

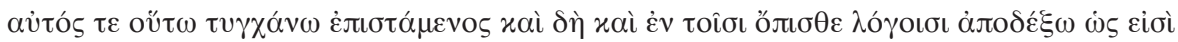
"E 
propersa - con el testimonio que Heródoto mismo en primera persona (aủ ós) ofrecerá a continuación acerca de la filiación helénica de la dinastía de Perdicas. Para ello, Heródoto trae a colación la participación de Alejandro en los Juegos Olímpicos, donde el rey macedonio se ve obligado a esgrimir sus credenciales griegas ante la acusación de los otros competidores quienes aducían "que la competencia no era para contrin-

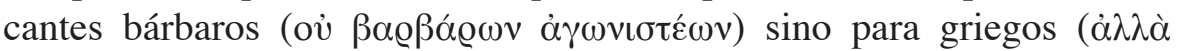

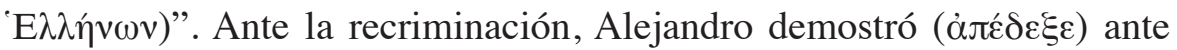
los ciudadanos eleos que presidían los Juegos Olímpicos ( $E \lambda \lambda \eta v o \delta i ́ x \alpha \iota)$ que él era de origen argivo, de modo que fue admitido en la competencia, tras lo cual resultó victorioso en la carrera. ${ }^{48}$ Independientemente de las discusiones en torno de la veracidad de la participación de Alejandro en los Juegos Olímpicos, vemos que la estrategia narrativa de Heródoto consiste en subrayar la ambivalencia identitaria de Alejandro: por un lado, la alianza por matrimonio con los persas, acerca de la cual Heródoto insistirá en VIII, 136.1, posiciona a Alejandro como cercano a los persas; por otro, Heródoto refrenda a título personal la adscripción étnica helénica del macedonio. La misma duplicidad se desprende de la interpretación del episodio de la recepción de los embajadores persas: si Alejandro reivindica nómoi típicamente griegos en las disposiciones del simposio, tanto la ambientación del banquete real macedonio como el accionar desmedido de Alejandro parecerían enfatizar ciertas afinidades con un éthos bárbaro, caracterizado por la propensión a la hýbris.

2) La declaración de Alejandro ante los embajadores persas resulta ambigua también en lo que atañe a su atribución. En efecto, ¿quién es el "griego, gobernante de Macedonia" que recibió bien a los persas en la mesa y en el lecho? El contexto del pasaje permite aquí también una doble interpretación: podría tratarse de que Alejandro estuviera aludiendo a sí mismo o bien a su padre, Amintas. Una lectura más bien lógica llevaría a pensar que Alejandro — puesto que es aún un joven y no detenta efectivamente el cargo de rey- estaría haciendo referencia a su padre. Es decir que Alejandro estaría literalmente 'hablando en nombre' de su padre, a quien le atribuye la 'hospitalaria' recepción de los persas (y, por extensión, las connotaciones irónicas que el enunciado reviste a la luz del crimen que se trae entre manos). Sin embargo, como he-

${ }^{48}$ En relación con la presunta participación de Alejandro en los Juegos Olímpicos, cf. Sourvinou-Inwood 2002; Badian 1994, pp. 120-1; Fearn 2007, pp. 116-8; J. Hall 2001, pp. 167-9. 
mos visto, Amintas es explícitamente corrido de la escena por el joven príncipe, tras lo cual desaparecerá del horizonte del relato. Dicho gesto transforma a Alejandro en el protagonista de los acontecimientos, quien inmediatamente se inviste de una autoridad suficiente como para digitar y llevar a cabo un crimen — ¿políticamente inconveniente? - a espaldas de su padre. La completa desaparición de Amintas y el protagonismo exclusivo que adquiere su hijo tanto en el desenlace del episodio como en el resto del relato permiten también leer la declaración de Alejandro como un símbolo del traspaso dinástico o la manifestación pública de una nueva identidad. En esta lectura, el "griego gobernador de Macedonia" refiere no ya a Amintas, sino a su descendiente Alejandro, quien adopta 'la voz de autoridad' real frente a los persas. En todo caso, se trata de una declaración efímera, en cuanto que el anuncio jamás llegará a oídos del Gran Rey; los embajadores perecerán tras la proclamación de la sentencia. En síntesis, la efectiva atribución de referente (Amintas o Alejandro) en lo que respecta al "griego gobernador de Macedonia" es deliberadamente equívoca. Equivocidad que caracteriza el lógos de Alejandro, a la vez rey y no-rey; griego y no-griego; colaborador con el persa y con los griegos; un personaje que trasvasa continuamente las 'fronteras' identitarias del relato.

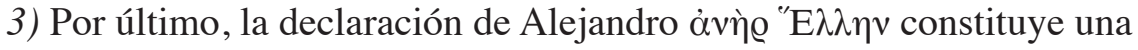
proclama explícita de una filiación identitaria con el mundo griego. Filiación ésta que a continuación Heródoto corrobora en primera persona mediante su alusión a la participación de Alejandro en los Juegos Olímpicos y al linaje argivo de los reyes macedonios. Asimismo, retomará la cuestión del linaje de los reyes macedonios en VIII, 136-9. En efecto, el interés en precisar las fronteras simbólicas de Macedonia en el relato, entre lo griego y lo bárbaro, caracteriza las sucesivas presentaciones de Alejandro. Hemos visto que el microrrelato sobre la recepción de los embajadores, así como los parágrafos siguientes, es ostensiblemente ambiguo en lo que respecta a las lealtades de los macedonios. La escena del simposio sugiere una práctica macedonia afín a las dinámicas de convivialidad intra e interaristocráticas de las póleis griegas arcaicas, pero cierto énfasis en los excesos o la voluptuosidad introduce un punto en que los nómoi macedonios y persas, caracterizados ambos pueblos por regímenes de tipo autocrático, no condicen plenamente con las costumbres 'griegas'. El corte introducido por Alejandro marca la diferencia con los nómoi persas en defensa de normas de convivialidad típicamente 
griegas, pero el acto mismo constituye una violación flagrante de las normas de hospitalidad. La relación política entre macedonios y persas oscila entre una complaciente posición de aceptación del poder persa y un reclamo de autonomía, es decir, entre la cooperación y la resistencia. ¿Cómo se debe entender, pues, esta proclama identitaria helénica puesta en boca de Alejandro? No nos detendremos aquí en la discutida 'etnicidad' de los macedonios planteada desde una perspectiva objetivista o primordialista, abordaje éste que ha intentado recabar evidencia lingüística, religiosa o cultural que pudiera dar cuenta del carácter 'griego' o 'no-griego' de los macedonios (o, como a menudo se ha sugerido, de una suerte de híbrido cultural en los márgenes entre la península griega y los Balcanes). ${ }^{49}$ Tampoco podemos ahondar aquí en los controvertidos testimonios griegos de época clásica que pueden arrojar luz sobre el grado de homogeneidad o inconsistencia en las fluctuantes percepciones de los autores antiguos sobre la etnicidad de los macedonios ${ }^{50}$ Creemos,

${ }^{49}$ Las dificultades que plantea este abordaje de la cuestión es, en primer lugar, que desatiende a la dimensión procesual y dinámica de las construcciones identitarias. En este sentido, la identidad étnica no puede establecerse una vez y para siempre en el devenir temporal, sino que evoluciona o fluctúa en función de criterios de auto-definición internos a la comunidad y a los contactos sucesivos con 'otros'. En segundo lugar, el caso macedónico plantea dificultades adicionales en cuanto son escasas o apenas fragmentarias las fuentes literarias de origen macedónico. La mayor parte de los datos que se poseen provienen de fuentes griegas (atenienses) de período clásico o helenístico o de fuentes romanas tardías, con lo cual se trata más bien de 'percepciones externas' de la etnicidad macedónica, testimonios éstos que son más elocuentes en relación con la conceptualización griega del pueblo macedónico en sus diferentes períodos antes que evidencia de la autocategorización por parte del ingroup. Más allá de los obstáculos inherentes a la adopción de una perspectiva objetivista de la identidad étnica, la crítica por lo general concuerda en que 1) los macedonios formaban parte hacia el siglo $\mathrm{v}$ de un espacio cultural griego en sentido amplio; 2) las evidencias epigráficas demuestran el uso del alfabeto y lengua griega; 3 ) el lenguaje oral de los macedonios sería una suerte de dialecto griego; 4) existían estrechas conexiones entre los nombres de los dioses macedónicos y el panteón griego. Cierto es que estas evidencias 'objetivas' poco pueden indicar sobre la autodefinición étnica de los propios macedonios. Para un tratamiento crítico de estos abordajes, con abundantes referencias bibliográficas, véase J. Hall 2001.

${ }^{50}$ La cuestión de la 'etnicidad' de los macedonios —o más estrictamente, de la percepción griega de la etnicidad macedonia - ha sido un punto debatido sobre el cual incluso las fuentes antiguas discrepan. Un análisis del conjunto de la evidencia nos permite concluir que prima, por lo general, una percepción del pueblo macedonio más bien como una suerte de 'híbrido' — vinculado, pero al mismo tiempo diferenciado, de los helenos. Tomemos apenas algunos ejemplos significativos. En el Catálogo de las Mujeres, una obra compilada hacia fines del siglo vI, atribuida en la Antigüedad a Hesíodo y 
no obstante, que el episodio de recepción de los embajadores persas en la corte macedonia, que concluye con la auto-designación de Amintas o Alejandro como 'griegos', nos permite ilustrar el carácter discursivo de la etnicidad.

a) En primer lugar, debemos precisar que el testimonio de Heródoto no ofrece datos fidedignos acerca de la identidad étnica de los macedonios per se —identidad ésta que sólo podría indagarse a partir de evidencia de origen macedonio-, sino únicamente un reflejo de las percepciones griegas de un historiador del siglo v, es decir, una 'construcción' ad hoc de la etnicidad macedonia derivada probablemente de datos recabados de fuentes locales pero también sujeta a un marcado proceso de reelaboración y ficcionalización en función de una estructura de trama.

b) En segundo lugar, existe una evidente preocupación por parte del historiador en relación con la identidad étnica o cultural de los macedonios, que se articula en torno de la figura de Alejandro I como dramatis persona. Según hemos visto, la presentación y ulterior participación del monarca macedonio en los acontecimientos se ve signada por la duplicidad, ambivalencia ésta que se proyecta en el plano de la identidad (personal) de Alejandro como participante circunstancial del desarrollo de los enfrentamientos entre griegos y bárbaros; así como — debemos

que procuraba sistematizar las diversas tradiciones genealógicas de Grecia, el ancestro de los macedonios es Macedón, hermano de Magnes e hijo de Zeus y Thuia, la hija de Deucalión (Hesíodo, fr. 7 MW). Helánico, hacia finales del siglo v, hace a Macedón hijo de Éolo, un hijo de Héleno y ancestro de los eolios, de modo que lo inscribe en la estirpe de los helenos (FRG 4 F 74). Durante la época clásica los testimonios dan cuenta de una percepción diferencial entre griegos y macedonios. Por lo general, se los ubicaba en un tertium quid entre la 'helenidad' y la 'barbarie'. Por un lado, se los distinguía de las comunidades efectivamente bárbaras, como los ilirios (Tuc., IV, 125.1; Diod., XII, 30.3; XV, 13.3), peonios (Hdt., V, 13.2; Diod., XVI, 4.2; Pausanias, V, 1.5) y tracios de la península griega (Aristófanes, Arcan., 168; Aves, 199; Diod., XV, 36.4; XVI, 71.2). Las observaciones circunstanciales de Tucídides se han prestado a controversias (cf. Sourvinou-Inwood 2002; Hornblower 1996, II, pp. 390-32). Por un lado, Tucídides (II, 99.3) parece admitir la descendencia helénica de los monarcas macedonios, pero no de sus súbditos. En II, 80.5-6, se mencionan las fuerzas macedónicas de Perdicas a

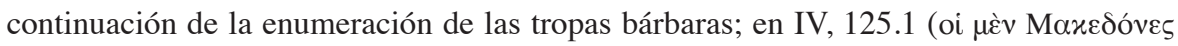

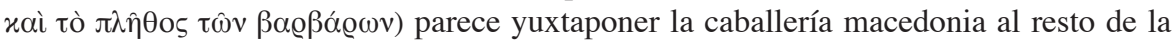
muchedumbre bárbara, sin resultar claro si efectivamente se está señalando una relación de equivalencia o introduciendo una distinción. Al problema de la heterogeneidad o ambigüedades de las fuentes, se suman los intereses político-ideológicos que pueden haber incidido en las referencias antiguas a los macedonios así como los criterios de definición de la identidad étnica en cada caso. 
entender por carácter transitivo- de la identidad (social) de los macedonios como pueblo.

c) Por último, la presentación de los macedonios en el contexto del libro $\mathrm{V}$ permite avizorar el carácter dinámico y fluido de la conformación de la identidad étnica, proceso éste que se despliega en un espacio simbólico de 'frontera'. Por un lado, el episodio de contacto entre macedonios y persas pone en evidencia el carácter procesual o relacional de la conformación de la identidad étnica. En efecto, es sólo a partir de la interacción con el otro cómo se definen las 'fronteras simbólicas': tras la irrupción de los nómoi persas en el contexto del simposio, que resultan disruptivos de un sentimiento de identidad cultural, se instaura una diferencia que posibilita la cristalización de un éthos macedónico y la concomitante toma de conciencia de una identidad de grupo (autocategorización). Por otro, la proclama étnica de Alejandro hacia el final del episodio pone de relieve la naturaleza discursiva de dicha identificación. En otras palabras, lo que determina una cierta identidad étnica - siguiendo las formulaciones de Barth — no es definible en términos objetivos de 'contenidos' culturales sino más bien en términos de una 'identificación' que se materializa a partir de su enunciación concreta. ${ }^{51}$ En este sentido, el episodio ilustra que, a nivel de las prácticas sociales, griegos, macedonios y persas se asemejan o diferencian recíprocamente en grados variables, de allí las ambigüedades que plantea el microrre-

${ }^{51}$ Una noción teórica que resulta insoslayable en cualquier abordaje de la etnicidad es la idea de 'fronteras' (boundaries) introducida por Fredrik Barth 1969. La aportación de Barth constituyó un punto de inflexión en la materia en la medida que desplazó la mirada antropológica, que solía identificar al grupo étnico con determinados atributos culturales, hacia las 'fronteras' que dividen un grupo de otro. Es decir, la tradicional concepción del grupo étnico como reductible a una sumatoria de 'contenidos' culturales específicos que lo definirían como tal fue cuestionada por Barth, quien propuso, en cambio, dirigir la atención hacia los mecanismos de interacción y de oposición entre grupos. En este sentido, los atributos que distinguen una y otra comunidad de pertenencia se constituyen a partir de un proceso de auto-atribución y de atribución externa por parte de los 'otros' (Barth 1969, pp. 9-38) y no pueden describirse en términos de 'contenidos' culturales estables e invariables del grupo étnico en sí. Lo que prevalece como (relativamente) estable, pues, no son tanto los atributos culturales de un grupo étnico — que, por otra parte, pueden ser compartidos por miembros de 'otros' grupos- cuanto la 'idea' de grupo en sí, que supone el reconocimiento e identificación de los miembros de una comunidad con tal identidad étnica y no otra. En este sentido, Barth propone una concepción relacional y procesual de la identidad étnica, articulada en torno a la demarcación y mantenimiento de las fronteras étnicas entre comunidades. 
lato en relación con la distinción de un modo de conducta típicamente griego o no-griego en el desarrollo del simposio y la recepción de los huéspedes. Es sólo a partir de la autodesignación de Alejandro como 'griego' —fundada en su inscripción en un linaje, que Heródoto se ocupa de precisar a continuación-que se instala la diferencia.

\section{Consideraciones finales}

El microrelato de la recepción y castigo de los embajadores persas por parte de Amintas y su hijo Alejandro introduce, como hemos sugerido, un 'corte' en varios niveles de la narratio herodotea. En efecto, a nivel estructural, el episodio se inscribe en el tránsito entre los libros IV y VI - en un spatium narrativo en el que la crítica vislumbró un pasaje entre los lógoi iniciales, en los que se ha reconocido un interés más propiamente etnográfico-descriptivo, y los lógoi finales, en que despuntaría un Heródoto 'historiador' -.${ }^{52}$ No sólo traza el límite estructural entre el libro IV y el VI, sino que marca también la transición entre la época arcai-

52 Tomamos la tradicional distinción inaugurada por Jacoby (1913, c. 281-396) quien pone el acento en el devenir-historiador de Heródoto. Jacoby pone el acento en la ruptura entre el primer Heródoto, tributario de Hecateo y los logógrafos jónicos, y el segundo Heródoto, historiador de las Guerras Médicas. El enfoque 'analista' iniciado por Jacoby ha sido cuestionado por la línea 'unitarista', que pone su acento en la 'unidad' de propósito de la obra, insistiendo sobre su coherencia temática o estructural. En relación con el debate entre analistas y unitaristas, adoptaremos aquí una posición matizada. Ni suscribiremos la idea de que la obra fue compuesta íntegra e intempestivamente al final de la vida del historiador, a partir de bosquejos o notas parciales (unitarismo radical: Kirchoff 1878; Powell 1939; Lattimore 1958); ni aquella, totalmente opuesta (fragmentarismo radical), que sostiene que la obra no ofrece más que un marco para relatos misceláneos enlazados (Aly 1921, p. 262; Howald 1945, pp. 41-3). Tampoco creemos que pueda sostenerse la premisa — tácitamente asumida por los unitaristas- de que las Historias constituyan 'un proyecto total' a priori a partir del cual Heródoto recopiló materiales diversos y organizó sus sucesivas excursiones etnográficas. Esto no significa, con todo, que el texto, en su versión final, no haya sido sometido a revisión y edición por parte del propio autor con miras a una unidad de propósito, cuyo eje central serían las así llamadas 'Guerras Médicas'. Creemos que existen tanto a) marcas textuales del prolongado proceso de composición de la obra — que excluye la posibilidad de una escritura final de la obra in toto así como la existencia de un proyecto orgánico madurado tempranamente-; $b$ ) indicios de un propósito de conjunto en la secuenciación final de la obra, es decir, del texto final como producto, que excluye asimismo la posibilidad de considerar el todo como una débil armazón para relatos misceláneos 
ca y la época clásica. En segundo lugar, hemos destacado la ambigüedad o ambivalencia que domina la presentación de los acontecimientos in situ, la caracterización de los personajes involucrados - especialmente Alejandro I-, y el lenguaje utilizado por la voz narradora en la escenificación del encuentro entre macedonios y persas. En particular, hemos argumentado que dicha ambigüedad o ambivalencia se expresa en varios planos. En primer lugar, señalamos que el esquema conceptual y el lenguaje de la xenía como mecanismo de conceptualización y codificación de los contactos entre pueblos, del cual se sirve aquí Heródoto para encuadrar el contacto entre macedonios y persas, aparece disputado, hecho éste que sugiere su agotamiento o inadecuación como modo de representar las relaciones con el 'otro' en el relato. En efecto, es a partir del significante nómos que, según vimos, irrumpe esta differentia en los mecanismos de socialización inter-aristocráticos y se abre en el relato una nueva modalidad de concebir al otro - no ya como un igual de clase, sino como el enemigo étnico-cultural- En segundo lugar, hemos analizado las ambigüedades inherentes al apóstrofe final de Alejandro a los embajadores persas y el modo en que se instituye como una ambivalente auto-proclamación identitaria tanto a nivel individual como de la identidad social de los macedonios. En lo que respecta a Alejandro, la proclama identitaria anticipa la duplicidad del personaje en su posterior accionar en la trama. En relación con la caracterización del pueblo macedonio en las Historias en su conjunto, el episodio del libro V ilustra la ambigüedad con la que Heródoto caracteriza al ser-macedónico, en un interregno entre lo 'griego' y lo ‘bárbaro'. Más aún, el episodio pone en evidencia no sólo el carácter procesual o relacional de la conformación de la identidad étnica —que en el relato se expresa como la 'toma de conciencia' del nómos como principio de diferenciación_, sino especialmente su naturaleza 'discursiva'. Es sólo a partir de la autoproclama de Alejandro como 'griego' — por oposición al ‘otro’ persa— que se logra cristalizar un sentimiento de identidad étnica. 


\section{BIBLIOGRAFÍA}

\section{Ediciones y traducciones}

Los pasajes de Heródoto citados en nuestro estudio corresponden a la edición de Alfred Godley, Herodotus, with an English translation, Cambridge, Mass., Harvard University Press, 1946. También se han consultado las siguientes ediciones, traducciones, comentarios y estudios generales:

Herodotus; the Histories, translated and introduced by Harry Carter, London, Oxford University Press, 1962.

Herodoti Historiae, recognovit brevique adnotatione critica instruxit Carolus Hude, Oxford, Oxford Classical Texts, 1927.

Hérodote, Histoires, texte établi et traduit par Philippe-Ernest Legrand, Paris, Les Belles Lettres, 1932-1954.

Herodoti, Historiae, edidit Haiim B. Rosén, Stuttgart / Leipzig, Teubner (I 1987; II 1997).

Heródoto. Historia I-IX, traducción y notas de Carlos Schrader, Madrid, Gredos, 2000.

Herodotus. The Histories, translated by Aubrey De Selincourt, Harmondsworth, Penguin, 1954.

Herodotos, erklärt von Heinrich Stein Berlin, 1889-1902.

The Histories of Herodotus, translated by George Rawlinson, London, Dent Redford, 1964.

Aristophanes, Comoediae, vol. 2, ed. F. W. Hall and W. M. Geldart, Oxford, Clarendon Press, 1907.

Diodorus Siculus, Diodorus of Sicily in Twelve Volumes, vols. 4-8, with an english translation by C. H. Oldfather, Cambridge / London, Harvard University Press / William Heinemann Ltd., 1989.

Hesiod, The Homeric Hymns and Homerica, with an english translation by Hugh G. Evelyn-White, Cambridge, Harvard University Press, 1924.

-, Works and Days, Cambridge / London, Harvard University Press, William Heinemann Ltd., 1914.

Justino/Pompeyo Trogo, Epitome de las Historias filípicas de Pompeyo Trogo, pról., frags., intr., trad. y nts. José Castro Sánchez, Madrid, 1995.

Pausanias, Pausaniae Graeciae Descriptio, Leipzig, Teubner, 1903, 3 vols.

PINDAR, The Odes of Pindar including the Principal Fragments, with an introduction and an english translation by John Sandys, Litt. D., FBA, Cambridge, London, Harvard University Press / William Heinemann Ltd., 1937.

THUCYDIDES, Historiae in Two Volumes, edited by Henry Stuart Jones and Johannes Enoch Powell, Oxford, Oxford University Press, 1942. 


\section{Estudios}

BADIAN, Ernst, "Herodotus on Alexander I of Macedon: A Study in Some Subtle Silences", en Simon Hornblower (ed.), Greek Historiography, Oxford, Oxford University Press, 1994, pp. 107-30.

BALCER, Jack, "Persian Occupied Thrace (Skudra)", Historia, 37, 1988, pp. 1-21.

BARTH, Fredrik, Ethnic Groups and Boundaries: The Social Organisation of Culture Difference, Bergen / London, Universitetsforlaget, 1969.

BorZA, Eugene, In the Shadow of Olympus: The Emergence of Macedon, Princeton, Princeton University Press, 1990.

BowIE, Angus, "Fate May Harm Me, I Have Dined Today: Near-Eastern Royal Banquets and Greek Symposia in Herodotus", en Symposium: banquet et représentations en Grèce et à Rome (Pallas 61), Colloque international, Université de Toulouse-Le Mirail, 2003, pp. 99-109.

Briant, Pierre, Histoire de l'empire perse. De Cyrus à Alexandre, Paris, Fayard, 1996.

CARnEY, Elizabeth, "Symposia and the Macedonian Elite: The Unmixed Life", Syllecta Classica, 18, 2007, pp. 129-80.

ERrington, Robert, "The Nature of the Macedonian State under the Monarchy", Chiron, 8, 1978, pp. 77-133.

- "Alexander the Philhellene and Persia", en Harry Dell (ed.), Ancient Macedonian Studies in Honor of Charles F. Edson, Inst. for Balkan Studies, Thessaloniki, 1981, pp. 139-43.

FEARN, David, "Narrating Ambiguity: Murder and Macedonian Allegiance (5. 17-

22)”, en Elizabeth Irwin y Emily Greenwood (eds.), 2007, pp. 98-127.

FINLEY, Moses, The World of Odysseus, New York, Viking Press, 1954.

GreEnwood, Emily, "Bridging the narrative (5. 23-7)", en Elizabeth Irwin y Emily Greenwood (eds.), 2007, pp. 128-45.

HAmmond, Nicholas \& Guy GrifFith, A History of Macedonia 2, Oxford, Clarendon Press, 1979.

Hall, Jonathan, "Contested Identities: Perceptions of Macedonia within Evolving Definitions of Greek Identity", en Irad Malkin (ed.), Ancient Perspectives of Greek Ethnicity, Cambridge, Harvard University Press, 2001, pp. 159-186.

Hartog, François, Le miroir d' Hérodote. Essai sur la représentation de l'autre, Paris, Gallimard, 1980.

Herman, Gabriel, Ritualised Friendship and the Greek City, Cambridge, Cambridge University Press, 1987.

Hornblower, Simon, Greek Historiography, Oxford, Clarendon Press, 1996.

IRWIN, Elizabeth, "What's in a name? and Exploring the Comparable: Onomastics, Ethnography and Kratos in Thrace (5. 1-2 and 3-10)", en Elizabeth Irwin y Emily Greenwood (eds.), 2007, pp. 41-87.

- y Emily Greenwood (eds.), Reading Book V. A Study of the Logoi in Book 5 of Herodotus' Histories, Cambridge, Cambridge University Press, 2007. 
JАСОвy, Felix, "Herodotos", en Paulys Real-Enyclopädie der classischen Altertumswissenschaft, ed. W. Kroll, Supplement-Band I I, Stuttgart, 1913, pp. 205-520. KIRCHOFF, Adolf, Studien zur Geschichte des grieschischen Alphabets, Berlin, 1878. KuHrT, Amélie, "Earth and Water", en Amélie Kuhrt y Helen Sancisi-Weedenburg (eds.), Achaemenid History 3, Leiden, Nederlands Instituut Voor Het Nabije Oosten, 1988, pp. 87-99.

LatTimore, Richmond, "The Composition of the History of Herodotus", Classical Philology, 53, 1958, pp. 9-21.

Mitchell, Lynette, Greeks Bearing Gifts: The Public Use of Private Relationships in the Greek World, 435-323 B. C., Cambridge, Cambridge University Press, 1997.

Murray, Oswyn, "The Symposion as Social Organization”, en R. Hägg (ed.), The Greek Renaissance of the Eighth Century B. C.: Tradition and Innovation, Stockholm, Aströms, 1983, pp. 195-9.

-, Sympotica: A Symposium on the Symposion, Oxford, Oxford University Press, 1990.

- "Sympotic History", en Oswyn Murray (ed.), Sympotica: A Symposium on the Symposion, Oxford, Oxford University Press, 1990, pp. 3-13.

NENCI, Giuseppe, "La formula della richiesta della terra e dell'acqua nel lessico diplomatico achemenide", en Maria Gabriella Angeli Bertinelli y Luigi Piccirilli (eds.), Linguaggio e terminologia diplomatica dall'antico Oriente all'Impero Bizantino, Roma, L'Erma di Bretschneider, 2001, pp. 31-42.

PITT-RIVERS, Julian, "The Kith and the Kin”, en Jack Goody (ed.), The Character of Kingship, Cambridge, Cambridge University Press, 1973, pp. 89-105.

Powell, J. Enoch, The History of Herodotus, Cambridge, Cambridge University Press, 1939.

Schmitt-PAntel, Pauline, La cite au banquet: Histoire des repas publics dans les cités grecques, Collection de l'École française de Rome ${ }^{\circ} 157$, Rome-Paris, 1997.

SмYтн, Herbert Weir, Greek Grammar, Cambridge, Harvard University Press, 1984.

SourvinOu-Inwood, Christiane, "Were the Macedonians Ethnically Greek?”, en Luisa Castelnuovo (ed.), Identità e prassi storica nel Mediterraneo greco, Milano, Edizioni ET, 2002, pp. 173-203.

TrIPODI, B., 'Aminta I, Alessandro I e gli hyparchoi in Erodoto', Ancient Macedonia, 7, 2007, pp. 75-86.

Wiesehöfer, Josef, Ancient Persia from 550 B. C. to 650 A. D., London / New York, I. B. Tauris Publishers, 1996. 